\title{
Snack extrusado a base de arroz com Spirulina platensis e farinha mista de
} subprodutos de laranja e palmito pupunha

Extruded rice-based snack with Spirulina platensis and mixed flour of orange and peach pallm byproducts

Snack extruido a base de arroz con Spirulina platensis y harina mixta de subproductos de naranja y palma pupunha

\section{Resumo}

Alimentos tipo snacks obtidos por extrusão podem ser adicionados de subprodutos agroindustriais, alternativa de baixo custo para incrementar o valor nutricional, e Spirulina platensis (SP) fonte de proteínas e antioxidantes. Neste estudo foram desenvolvidos snacks, usando delineamento experimental $2^{2}$ onde se testou as variáveis SP (S. platensis) - 2,5 a 7,5 g.100 $\mathrm{g}^{-1}$ e umidade de alimentação (U) - 18 a $26 \mathrm{~g} .100 \mathrm{~g}^{-1}$. As formulações continham farinha de arroz (Oryza sativa L.) (72,5 a 77,5 g.100 g $\mathrm{g}^{-1}$ ) e $20 \mathrm{~g} .100 \mathrm{~g}^{-1}$ da mistura de farinha de subprodutos de laranja (FL) (Citrus sinensis L. Osbeck) e de palmito pupunha (FP) (Bactris gasipaes) (1:1). Os snacks foram avaliados quanto aos parâmetros nutricionais, tecnológicos e sensoriais. Verificou-se que a SP aumentou o teor de proteínas e antioxidante das formulações. Quando comparados a um produto comercial similar, os snacks continham de 15-48 \% mais proteínas, e 320-380\% a mais de fibras alimentares. O aumento de SP, elevou em mais de $1000 \%$ a atividade antioxidante dos snacks. Nas condições testadas a densidade aparente foi diretamente proporcional à $U$, enquanto, dureza e crocância foram inversamente proporcionais. No entanto, as variáveis SP e U não interferiram nos índices de expansão, solubilidade em água, absorção de água e absorção de óleo. As maiores aceitações sensoriais, de 72 e $73 \%$, ocorreram em condição de maior incorporação de SP. Assim, mostrou-se a possibilidade de elaboração de snacks sem glúten com valor nutricional superior aos similares comercializados, para consumidores atentos à dieta mais saudável, além de alternativa de aproveitamento de subprodutos. Palavras-chave: Crocância; Expansão; Enriquecimento nutricional; Fibras alimentares; Compostos bioativos.

\begin{abstract}
Snacks obtained by extrusion can be added with agro-industrial by-products, a low-cost alternative to increase nutritional value, and Spirulina platensis (SP), a source of proteins and antioxidants. In this study, extruded snacks were developed using a $2^{2}$ experimental design where variables S. platensis (SP) - 2.5 to $7.5 \mathrm{~g} .100 \mathrm{~g}^{-1}$ and feed moisture (M) - 18 to 26

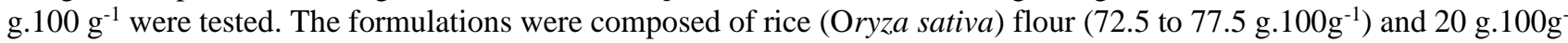
${ }^{1}$ of a mixture flour of orange (Citrus sinensis L. Osbeck) and peach palm (Bactris gasipaes) by-products (1:1). Snacks
\end{abstract}


were evaluated for nutritional, technological and sensory parameters. It was found that SP increased the protein and antioxidant content of the formulations. When compared to a similar commercial product, snacks contained $15-48 \%$ more protein, and 320-380\% more dietary fiber. The increase in SP increased the antioxidant activity of snacks by more than $1000 \%$. In the tested conditions, the apparent density was directly proportional to U, while hardness and crunchiness were inversely proportional. However, the SP and U variables did not affect the expansion rates, water solubility, water absorption and oil absorption. The highest sensory acceptance, of 72 and $73 \%$, occurred in a condition of greater incorporation of SP. Thus, the possibility of making gluten-free snacks with a higher nutritional value than those marketed was shown, for consumers aware of a healthier diet, as well as an alternative for the use of by-products.

Keywords: Crunchiness; Expansion. Nutritional enrichment; Dietary fibers; Bioactive compounds.

\section{Resumen}

Los subproductos agroindustriales se pueden agregar con snacks obtenidos por extrusión, siendo una alternativa de bajo costo para aumentar el valor nutricional, y la Spirulina platensis (SP) una fuente de proteínas y antioxidantes. En este estudio se desarrollaron snacks extruidos, utilizando un diseño experimental $2^{2}$ donde se probaron las variables SP - 2.5$7.5 \mathrm{~g} .100 \mathrm{~g}^{-1}$ y humedad de entrada (U) - 18-26 g.100 g $\mathrm{g}^{-1}$. Las formulaciones contenían harina de arroz (Oryza sativa L.) $\left(72,5-77,5\right.$ g. $\left.100 \mathrm{~g}^{-1}\right)$ y $20 \mathrm{~g} .100 \mathrm{~g}^{-1}$ de la mezcla de harina de subproductos de naranja (Citrus sinensis L. Osbeck) y palma pupunha (Bactris gasipaes) (1:1). Los snacks fueron evaluados por parámetros nutricionales, tecnológicos y sensoriales. Se encontró que SP aumentó el contenido de proteínas y antioxidantes. En comparación con un producto comercial, los snacks contenían entre 15-48\% más de proteínas y entre 320-380\% más de fibra dietética. El aumento de SP aumentó la actividad antioxidante de los snacks en más de $1000 \%$. En las condiciones probadas la densidad aparente fue directamente proporcional a U, mientras que la dureza y el crujido fueron inversamente proporcionales. Sin embargo, las variables SP y U no afectaron las tasas de expansión, la solubilidad en agua, la absorción de agua y la absorción de aceite. La mayor aceptación sensorial, del 72-73\%, se produjo en una condición de mayor incorporación de SP. Así, se mostró la posibilidad de elaborar snacks sin gluten con un valor nutricional superior a los comercializados, para consumidores conscientes de una dieta más saludable, así como una alternativa para el uso de subproductos.

Palabras clave: Crispness; Expansión. Enriquecimiento nutricional; Fibra alimentaria; Compuestos bioactivos.

\section{Introdução}

Alimentos extrusados, do tipo snacks, são consumidos por todas as faixas etárias de pessoas, no entanto, as principais formulações comerciais consistem em produtos de baixo valor nutricional e alto valor energético. A exploração de matrizes provenientes de subprodutos agroindustriais para elaboração de snacks extrusados vem crescendo no ramo científico e industrial, pois a diferenciação do produto explorando novas matérias-primas pode atender nichos de mercado que valorizam a sustentabilidade e propriedades nutricionais diferenciadas. Sobretudo, incorporar ingredientes que tornem os snacks extrusados mais nutritivos pode torná-los mais atrativos aos consumidores (Grasso, 2020).

Spirulina platensis é uma cianobactéria que tem sido estudada devido à sua importância comercial como fonte de proteínas, vitaminas, minerais, aminoácidos e ácidos graxos essenciais. É uma fonte de proteínas com alto valor biológico, considerada de boa digestibilidade, variando de 50 a $70 \%$ em base seca. Apresenta compostos bioativos com atividade antioxidante que auxiliam na redução do risco de diversas enfermidades (Lupatini et al., 2017; Ejike et al., 2017). A aplicação de S. platensis na formulação de produtos alimentícios, como cookies, massas, sopas, produtos de panificação, bebida láctea, sobretudo snacks tem mostrado resultados promissores em termos de aceitação sensorial e valor nutricional (Bolanho et al., 2014; Lemes, Takeuchi, Carvalho \& Danesi, 2012; Marco, Steffolani, Martínez \& León, 2014; Lemes, Takeuchi, Frata \& Danesi, 2016; Navacchi, Takeuchi \& Danesi, 2016; Guido, Correa \& Danesi, 2016; Lemes et al., 2016; Joshi, Bera \& Panesar, 2014; Morsy, Sharoba, El-Desouky, Bahlol, \& El-Mawla, 2014; Lucas, Morais Santos \& Costa, 2017, 2018; Tanska, Konopka \& Ruszkowska, 2017).

A incorporação de subprodutos agroindustriais pode promover o aumento de fibras alimentares e do valor nutricional de snacks extrusados. A farinha de arroz (Oryza sativa L.) é considerada um subproduto na indústria de arroz, geralmente ela é produzida a partir de grãos quebrados no processamento. A aplicação de farinha de arroz pode ser uma opção de substituição, total ou parcial, de fontes amiláceas tradicionais na elaboração de alimentos extrusados, como farinha de milho ou de trigo, pois, apresenta melhor composição de aminoácidos essenciais e proteínas de boa digestibilidade, isenta de glúten, além de conferir vantagens tecnológicas e sensoriais, como capacidade de expansão, cor branca e sabor suave (Walter, Marchezan \& Avila, 2008; 
Kadan, Robinson, Thibodeaux, \& Peppermen, 2001). Na extração do suco de laranja (Citrus sinensis L. Osbeck), 50\% dos frutos consistem de resíduos sólidos, como farelo da polpa, polpa, óleo e terpeno cítrico. No processamento do palmito pupunha (Bactris gasipaes) na forma de conservas são gerados até $84 \%$ de subprodutos. Quando transformados em farinhas, estes materiais representam uma forma de valorização do produto, pois são ricas em fibras alimentares e compostos bioativos que as tornam atrativas na formulação de produtos para alimentação humana (Romero-Lopez, Osorio-Diaz, Bello-Perez, Tovar, \& BernardinoNicanor, 2011; Bolanho, Danesi \& Beléia, 2014).

Não há relatos de estudos de desenvolvimento de snacks extrusados com a aplicação dos subprodutos de arroz, laranja e palmito pupunha com S. platensis de forma conjunta. Os snacks extrusados com farinha de arroz e de milho com S. platensis a 2,6\%, no estudo de Lucas et al. (2018), continham 9,6\% a mais de proteínas que a amostra controle. Navarro-Cortez et al. (2016) verificaram que a adição de $25 \%$ de bagaço de laranja (C. sinensis) em extrusados de fubá milho (Zea mays L.) aumentou em até 226,6\% o conteúdo de fibras. Não foram encontrados estudos de aplicação do subproduto da produção de palmito pupunha para elaboração de extrusados, apenas a aplicação da farinha dos frutos de pupunha (Santos et al., 2020).

Desse modo, o desenvolvimento de snacks extrusados usando farinhas mistas compostas dos subprodutos de arroz, laranja e palmito pupunha com inclusão de S. platensis constitui no objetivo deste estudo. A avaliação do comportamento tecnológico, nutricional e sensorial destas formulações é importante para determinar a viabilidade desta aplicação.

\section{Metodologia}

\section{Materiais}

Os subprodutos de palmito pupunha (Bactris gasipaes) foram doados pela indústria de processamento de palmito pupunha em conservas Marbbel, de Antonina, PR. Arroz branco quebrado (Oryza sativa L.) (Urbaninho ${ }^{\circledR}$ ), laranja pêra (Citrus sinensis L. Osbeck), Cloreto de sódio $\left(\right.$ Cisne $\left.^{\circledR}\right)$ e azeite de oliva extra virgem $\left(\right.$ Gallo $^{\circledR}$ ) foram adquiridos em comércio de Ponta Grossa, PR e Spirulina platensis na BioMundo de Brasília, DF, Brasil. Salsinha (Petroselinum crispum) fresca foi obtida na horta da Universidade Estadual de Ponta Grossa - UEPG, desidratada a $60{ }^{\circ} \mathrm{C}$ e moída.

Foram utilizados os produtos químicos: ácido gálico, 2,2-difenil-1-picrilhidrazila (DPPH`), reagente de Folin-Ciocalteu 2 N, tampão MES-TRIS (MES hydrate e TRIZMA ${ }^{\circledR}$ BASE) adquiridos da Sigma-Aldrich (São Paulo, Brasil). Ácido ascórbico, carbonato de sódio, ácido sulfúrico, álcool etílico, álcool metílico, cloreto férrico hexahidratado, ferricianeto de potássio, ácido clorídrico, hexano e acetona foram adquiridos da Vetec (Rio de Janeiro, Brasil) e hidróxido de sódio da Synth (Diadema, Brasil). Protease (ProteMax 580L), $\alpha$-amilase (StarMax TG120), amiloglicosidase (amiloglicosidase (StarMax GA 400) foram doados pela $\operatorname{Prozyn}^{\circledR}$ (São Paulo, Brasil).

\section{Processamento das farinhas dos subprodutos agroindustriais}

A farinha de arroz (FA) foi obtida a partir de arroz branco quebrado processado em moinho de facas (M20; IKA ${ }^{\circledR}$, USA). Os frutos de laranja e os subprodutos de palmito pupunha foram submetidos à lavagem e sanitização com solução clorada a 100 mg. $\mathrm{L}^{-1}$ por 15 min. Foi feita remoção manual das cascas das laranjas. Os frutos foram cortados ao meio e o suco extraído em prensa hidráulica (Ribeiro, Brasil) com pressão de $164 \mathrm{kgf} . \mathrm{cm}^{-2}$ por $3 \mathrm{~min}$. Os subprodutos de laranja foram cortados em tiras e submetidos à secagem por convecção de ar forçado (modelo: MA035; Marca: Marconi, Piracicaba) a $80{ }^{\circ} \mathrm{C}$. A farinha de subprodutos de laranja (FL) consistiu de albedo, membrana e vesículas. A farinha de subproduto de palmito pupunha (FP) foi obtida a partir da região caulinar do palmito. Após o corte foi feita a secagem em estufa com circulação de ar a $60{ }^{\circ} \mathrm{C}$. Depois de resfriar, os subprodutos foram triturados em moinho de facas (M20; IKA $\left.{ }^{\circledR}, \mathrm{USA}\right)$, cujas partículas apresentaram dimensões inferiores a 28 Tyler mesh (600 mm), adaptado de Larrea, Chang \& Martinez-Bustos (2005) e umidade de $10 \pm 2$ g. $100 \mathrm{~g}^{-1}$. 


\section{Planejamento experimental para formulação dos snacks}

As quatro formulações e três repetições do ponto central foram obtidas utilizando planejamento fatorial $2^{2}$, sendo as variáveis independentes Spirulina platensis (SP) e umidade de alimentação (U), para investigar o efeito do processo de extrusão nas respostas ou nas variáveis dependentes conforme Tabela 1 (Myers, Montgomery \& Anderson-Cook, 2016). Cada $100 \mathrm{~g}$ de formulação continha FA de 72,5 a 77,5 g, $20 \mathrm{~g}$ farinha mista de FL e FP na proporção 1:1, e 2,5 a 7,5 g de SP. A umidade de alimentação foi de 18 a $26 \%$ (g. $\left.\mathrm{g}^{-1}\right)$. A ordem de processamento das formulações ocorreu de maneira randomizada.

Tabela 1. Delineamento fatorial $2^{2}$ com repetição do ponto central.

\begin{tabular}{|c|c|c|c|c|c|}
\hline \multirow{2}{*}{ Fatores } & \multicolumn{5}{|c|}{ Níveis } \\
\hline & \multicolumn{2}{|l|}{-1} & \multicolumn{2}{|c|}{$\mathbf{0}$} & +1 \\
\hline $\mathbf{X}_{1}: \mathbf{S P}$ & \multicolumn{2}{|l|}{2,5} & \multicolumn{2}{|c|}{5,0} & 7,5 \\
\hline$X_{2}: \mathrm{U}$ & \multicolumn{2}{|l|}{18} & \multicolumn{2}{|c|}{22} & 26 \\
\hline \multirow{2}{*}{ Tratamentos } & \multicolumn{2}{|c|}{ Variáveis codificadas } & & \multicolumn{2}{|c|}{ Variáveis reais } \\
\hline & $\mathbf{X}_{1}$ & $\mathbf{X}_{2}$ & & $X_{1}: S P$ & $X_{2}: \mathrm{U}$ \\
\hline $\mathbf{A}$ & -1 & -1 & & 2,5 & 18 \\
\hline B & +1 & -1 & & 7,5 & 18 \\
\hline C & -1 & +1 & & 2,5 & 26 \\
\hline D & +1 & +1 & & 7,5 & 26 \\
\hline $\mathbf{E}$ & 0 & 0 & & 5,0 & 22 \\
\hline $\mathbf{F}$ & 0 & 0 & & 5,0 & 22 \\
\hline G & 0 & 0 & & 5,0 & 22 \\
\hline
\end{tabular}

Nota: $\mathrm{X}_{1}=$ concentração de Spirulina platensis $\left(\mathrm{g} .100 \mathrm{~g}^{-1}\right) ; \mathrm{X}_{2}=$ umidade de alimentação (g. $100 \mathrm{~g}^{-1}$ ). Fonte: Autores.

A massa de água necessária em cada experimento para o ajuste de umidade, conforme o planejamento, foi calculado pela Equação 1. A adição de água ocorreu de forma lenta, seguida de agitação por 30 min em batedeira com batedor plano (K45SS, Kitchen Aind ${ }^{\circledR}$, USA). As formulações foram armazenadas em sacos de polietileno e mantidas em refrigeração a $8{ }^{\circ} \mathrm{C}$ por $24 \mathrm{~h}$. Antecedendo o processamento, as formulações foram retiradas da refrigeração por uma hora, e mensurada a umidade por infravermelho (MA35, Sartorius, Alemanha) (Zortéa-Guidolin, Carvalho, Godoy, Demiate \& Scher, 2017; Ascheri, Ascheri \& Carvalho, 2006).

$$
Q a=\left[\frac{(100-U i)}{(100-U f)}-1\right] \times P a
$$

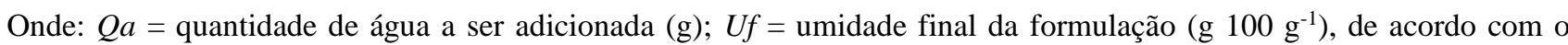

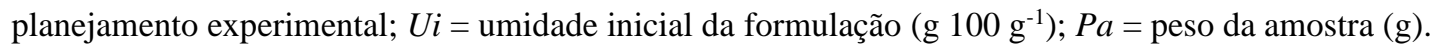

As formulações foram submetidas ao processo de extrusão em extrusora (Ex micro Lab, Exteec, Ribeirão Preto) através de fricção mecânica, rosca simples e sistema de refrigeração hidráulica para controle de temperatura na camisa de extrusão. Foram realizados testes preliminares para determinação dos parâmetros fixos assim definidos: taxa de alimentação $\left(15 \mathrm{~kg} . \mathrm{h}^{-1}\right)$; matriz de 1 furo e abertura circular com diâmetro de 3,1 mm; faca com duas lâminas e rotação das facas aproximadamente $15 \mathrm{~Hz}$ (Oliveira, Rosell \& Steel, 2015; Joshi et al., 2014).

Após o processo de extrusão, os snacks foram mantidos em temperatura ambiente por $20 \mathrm{~min}$, secos em estufa com convecção de ar forçado a $60{ }^{\circ} \mathrm{C}$ (MA035; Marconi, Piracicaba) até umidade de $4 \pm 1$ g. $100 \mathrm{~g}^{-1}$. Seguido do resfriamento, foram acondicionados em embalagem de polipropileno em freezer a $-18{ }^{\circ} \mathrm{C}$, para análises posteriores (Oliveira et al., 2015).

Uma porção de $300 \mathrm{~g}$ de cada formulação dos snacks foi acrescida de condimentos. A partir de testes preliminares a proporção de condimentos foi definida com azeite $\left(5 \mathrm{~g} .100 \mathrm{~g}^{-1}\right)$, cloreto de sódio $\left(3 \mathrm{~g} .100 \mathrm{~g}^{-1}\right)$ e salsinha desidratada $\left(1 \mathrm{~g} 100 \mathrm{~g}^{-1}\right)$ (Lucas, 2018). Os componentes foram homogeneizados e adicionados aos snacks com movimentos circulares, para agregação na 
camada superficial. Os snacks foram submetidos à secagem até umidade de $4 \pm 1 \mathrm{~g}$. $100 \mathrm{~g}^{-1}$, após resfriamento foram acondicionadas em embalagem Ziploc ${ }^{\circledR}$ e mantidos em temperatura ambiente até o momento da análise sensorial.

\section{Determinação da composição proximal}

A composição proximal foi determinada em base seca de acordo com a Association of Official Analytical Chemists (AOAC, 1995): umidade (método 925.10), cinzas (método 923.03), proteínas (método 960.52) com fator de conversão de 6,25, lipídios (método 920.39C), e carboidratos foram quantificados por diferença. Os teores de fibras solúveis e insolúveis (método 991.43). Os resultados foram expressos em g. $100 \mathrm{~g}^{-1}$ de snack. O valor energético (VE) foi determinado usando os fatores de Atwater (4 kcal. $\mathrm{g}^{-1}$ para carboidratos e proteínas, e $9 \mathrm{kcal} . \mathrm{g}^{-1}$ para lipídios), e expresso em kcal. $100 \mathrm{~g}^{-1}$ de snack.

\section{Determinação da composição fenólica e atividade antioxidante}

Os extratos etanólicos das farinhas arroz e de palmito pupunha (FA, FP) foram obtidos utilizando-se solução etanólica $(80 \%)$ e proporções 1:16 e 1:9 (g. $\left.\mathrm{mL}^{-1}\right)$, respectivamente, foram agitados por $4 \mathrm{~h}$. Para obtenção do extrato de farinha de laranja (FL) foi conduzido em solução etanólica $60 \%$, na proporção 1:10 (g. $\left.\mathrm{mL}^{-1}\right)$, a solução foi mantida em banho ultrassônico por 30 min a $25^{\circ} \mathrm{C}$. Os produtos da extração das farinhas foram centrifugados por 15 min a 7.10³ $x$ g (Modelo: Himac CR21GII, Hitachi, Japão), em seguida foi coletado o sobrenadante. Para a S. platensis (SP), foi feita uma suspensão aquosa (água ultrapura) na concentração $1 \mathrm{~g}$. L $\mathrm{L}^{-1}$, a solução foi mantida em banho ultrassônico por $1 \mathrm{~h}$, centrifugada por 15 min a $7.10^{3} x \mathrm{~g}$ (Modelo: Himac CR21GII, Hitachi, Japão), em seguida foi coletado o sobrenadante. A metodologia de extração foi proposta por Lupatini et al. (2017) com modificações. Os extratos foram diluídos em solução igual a de extração, e o fator de diluição foi conduzido de forma adequada para cada experimento.

Os extratos etanólicos dos snacks foram elaborados a partir da proporção 1:2 (g de amostra: mL de solução etanólica 50 $\%$ ), mantidos em vórtex por 5 min e centrifugados por $10 \mathrm{~min}$ a $7.10^{3} x \mathrm{~g}$ (mini Spin Plus, Eppendorf ${ }^{\circledR}$, Alemanha). O sobrenadante foi coletado e diluído 1:1 (v.v $\left.\mathrm{v}^{-1}\right)$ em solução etanólica 50 \%. A solução etanólica foi elaborada a partir de água ultrapura e álcool etílico $96 \%$ PA.

Os compostos fenólicos totais (CFT) dos extratos etanólicos foram quantificados seguindo o método Azul da Prússia (Margraf, Karnopp, Rosso \& Granato, 2015), e os resultados expressos em mg de ácido gálico equivalente por $100 \mathrm{~g}$ de snack (mg GAE. $100 \mathrm{~g}^{-1}$ ). A atividade antioxidante (AA) foi estimada pelo método de captura do radical DPPH (Santos et al., 2016; Granato, Karnopp \& Ruth, 2015; Brand-Williams, Cuvelier \& Berset, 1995), e os resultados expressos em percentual de inibição do radical DPPH•. A capacidade redutora do reagente Folin-Ciocalteu (CRFC) (Granato et al., 2015; Singleton, Orthofer \& LamuelaRaventós, 1999), e os resultados expressos em mg de ácido gálico equivalente por $100 \mathrm{~g}$ de amostra (mg GAE.100 g-1).

\section{Determinação dos parâmetros tecnológicos}

O índice de expansão (IE) expresso em \% (mm. $\left.\mathrm{mm}^{-1}\right)$ dos snacks foi avaliado no material após a extrusão e antes da secagem, em 20 medidas de cada tratamento e calculado pela equação 2 (Souza, Leonel \& Mischan, 2007; Alam, Pathania \& Sharma, 2016).

Onde: Ds = diâmetro do snack; Dm = diâmetro da matriz.

$$
I E(\%)=\frac{D s}{D m} \times 100
$$

A densidade aparente (DA) dos produtos expandidos foi determinada pelo método do deslocamento de massa ocupada por sementes de painço, a partir do quociente de massa, g, e volume, L, com dez amostras de cada formulação (Brito \& Cereda, 2015; Bolanho et al., 2014; Brennan, Monro \& Brennan, 2008). Os resultados foram expressos em g. $\mathrm{L}^{-1}$. 
O índice de absorção em água (IAA) dos snacks foi determinado conforme metodologia descrita por Anderson; Conway; Peplinski (1970), que consistiu em elaborar uma suspensão de $2,5 \mathrm{~g}$ de amostra em $30 \mathrm{~mL}$ de água a $30 \pm 2{ }^{\circ} \mathrm{C}$, mantido em agitação por 30 min em agitador, submetido à centrifugação a $2 \cdot 10^{3} x \mathrm{~g}$ durante $10 \mathrm{~min}$. Todo o sobrenadante foi coletado e seco em estufa a $105^{\circ} \mathrm{C}$ até peso constante. Os resultados foram expressos em g gel. $\mathrm{g}^{-1}$ snack. Para determinação do índice de absorção de óleo (IAO) houve substituição da água por óleo. O procedimento e cálculo realizado foram equivalentes ao de determinação do IAA (Fiorda, Soares, Silva, Moura \& Grossmann, 2015). Os resultados foram expressos em g. $100 \mathrm{~g}^{-1}$ snack. O índice de solubilidade em água (ISA) dos snacks foi calculado pela relação percentual entre o peso do resíduo de evaporação e o peso seco da amostra (Anderson et al., 1970). Os resultados foram expressos em g gel. $\mathrm{g}^{-1}$ snack.

A atividade de água $\left(\mathrm{A}_{\mathrm{w}}\right)$ foi determinada por higrômetro (Aqualab Series 3TE, Decagon Devices, Inc.), onde foi colocado $1 \mathrm{~g}$ da amostra no porta-amostra. Os resultados foram expressos em uma escala de 0 a 1.

As propriedades mecânicas, dureza e crocância, dos snacks foram determinadas por texturômetro (TA-XT Plus Texture Analyser, Stable Micro System, Godalming, UK) e probe HDP-BS. Foram escolhidas seis amostras aleatoriamente. Condições fixas estabelecidas: distância do probe de $45 \mathrm{~mm}$; velocidade do teste de $2 \mathrm{~mm} . \mathrm{s}^{-1}$; velocidade pós-teste de $10 \mathrm{~mm}$. $\mathrm{s}^{-1}$. O equipamento foi ajustado para medir a força de compressão. A dureza foi determinada pela força máxima de resistência à ruptura, expressa em Newton $(\mathrm{N})$, enquanto crocância foi determinada pelo número de picos gerados ao longo da curva (Oliveira, Schimiele \& Steel, 2017; Bender et al., 2016).

As determinações dos parâmetros instrumentais de cor, $L^{*}, a^{*}$ e $b^{*}$, foram realizadas em espectrofotômetro portátil (Miniscan EZ, Hunterlab®, EUA) de acordo com o sistema Cielab. Foram realizadas dez leituras para cada formulação (pó) e snacks correspondente. A diferença de cor $(\Delta \mathrm{E})$ entre as formulações e os snacks foi obtida pela Equação 3.

$$
\Delta E=\sqrt{\left(\Delta L^{* 2}\right)+\left(\Delta a^{* 2}\right)+\left(\Delta b^{* 2}\right)}
$$

Onde: $\Delta L^{*}=\left(\right.$ valor do parâmetro $L^{*}$ da formulação $)-\left(\right.$ valor do parâmetro $L^{*}$ do snack); $\Delta a^{*}=\left(\right.$ valor do parâmetro $a^{*}$ da formulação) - (valor do parâmetro $a^{*}$ do snack); $\Delta b^{*}=$ (valor do parâmetro $b^{*}$ da formulação) - (valor do parâmetro $b^{*}$ do $s n a c k$ ).

\section{Análise sensorial}

A análise sensorial dos snacks foi conduzida em cabines sensoriais iluminadas com luz branca e temperatura controlada, após aprovação pelo Comitê de Ética da Universidade Estadual de Ponta Grossa (CAAE nº 65857017.4.0000.5215). Foram recrutados aleatoriamente 75 avaliadores não treinados na Universidade Estadual de Ponta Grossa (UEPG), com idade entre 17 a 53 anos. O teste aplicado foi de escala hedônica estruturada em 9 pontos (1 - desgostei extremamente a 9 - gostei extremamente), para avaliar os atributos aparência, cor, odor, textura, sabor, e impressão global (ISO, 2014). O índice de aceitabilidade foi calculado pela razão entre a média obtida e nota máxima para impressão global, multiplicado por 100 (Damasceno et al., 2016). A análise microbiológica dos snacks foi realizada para garantir as condições higiênico-sanitária, onde foram analisados coliformes totais a 45 ${ }^{\circ} \mathrm{C}$ e Salmonella (Brasil, 2001; Goes et al. 2015).

\section{Análise dos dados}

Os experimentos foram realizados em triplicata, e os resultados expressos como média e desvio padrão. Diferenças significativas de médias foram determinadas por análise de variância unifatorial (one-way ANOVA). Os conjuntos de dados com distribuição normal $(p>0,05)$ e homocedásticos $(p>0,05)$ foram comparados pelo teste de comparação de médias Fisher LSD $(p \leq 0,05)$. O teste de Welch e o teste de Kruskal-Wallis (ambos $p \leq 0,05)$ foram aplicados em dados normalmente distribuídos com variância desigual (heterocedásticos) e amostras sem distribuição normal, respectivamente. A avaliação dos efeitos quantitativos 
nas variáveis independentes ( $S$. platensis e umidade de alimentação) nas respostas foi realizada por regressão linear múltipla, baseada na metodologia de superfície de resposta (MSR). Foram gerados modelos polinomiais de segunda ordem para explicar a influência dos efeitos lineares e de interação entre S. platensis (SP) e umidade de alimentação (U). Os gráficos de contorno bidimensional para cada variável de resposta foram gerados a partir dos coeficientes de regressão significativos. O software Statistica v. 13.3 (Statsoft, USA), foi usado para todas as análises estatísticas (Granato, Calado \& Jarvis, 2014; Bezerra, Santelli, Oliveira, Villar \& Escaleira, 2008).

\section{Resultados e Discussão}

\section{Composição proximal, fenólica e atividade antioxidante dos snacks}

A composição proximal, composição fenólica e atividade antioxidante dos snacks podem ser vistas na Tabela 2. Os teores de umidade variaram de 3,26-4,15, cinzas de 1,52-2,00, proteínas de 9,65-12,14, lipídios de 0,19-0,79, fibras alimentares totais de 8,49-9,75, onde fibras solúveis de 2,10-3,48 e fibras insolúveis de 4,85-7,65, expressos em g. $100 \mathrm{~g}^{-1}$. Os carboidratos variaram de 72,86 a 75,04 g. $100 \mathrm{~g}^{-1}$.

Os teores de proteínas dos snacks foram influenciados positivamente pela adição de S. platensis. A incorporação de Spirulina sp. em snacks tem sido relatada em diversos estudos, pela alegação de aumento do valor nutricional, principalmente, pelo aumento do conteúdo proteico (Joshi et al., 2014; Morsy et al., 2014; Lucas et al., 2017, 2018; Tanska et al., 2017).

Para fins comparativos foi verificada a tabela nutricional de um snack de arroz similar comercial (composição: Mix sem glúten (farinha de arroz, lentilha e quinoa), óleo vegetal (palma e soja), sal light, extrato de levedura, cebola, salsa, corante natural de urucum e aromas). Na tabela nutricional, uma porção de $25 \mathrm{~g}$ do produto contém $19 \mathrm{~g}$ de carboidratos, 2,1 g de proteínas, 1,8 g gorduras totais, e 0,5 g de fibra alimentar, totalizando um valor energético de $99 \mathrm{kcal}$ (Belive, 2021).

De acordo com a RDC nº 269 (Brasil, 2005), a Ingestão Diária Recomendada (IDR) de proteínas a um adulto é de 50 g. Uma porção do snack comercial pode contribuir em 4,2 \% das proteínas diárias recomendadas para um adulto, enquanto os snacks desenvolvidos neste estudo, podem contribuir de 4,8 a 6,2 \%. Isso representa um aumento de 15 a $48 \%$.

Os teores de fibras alimentares totais em uma porção variaram de 2,1 a 2,4 g. $25 \mathrm{~g}^{-1}$. A mistura de farinhas de subprodutos pode contribuir no aporte de fibras a partir da ingestão dos snacks extrusados desenvolvidos neste estudo, mas não podem ser classificados como alimento fonte de fibras (2,5 g/porção), em que a porção para petisco extrusado a base de cereais é de $25 \mathrm{~g}$ (Brasil, 2003). No entanto, quando os snacks desenvolvidos neste estudo são comparados a um produto extrusado comercial similiar (Belive, 2021) o aumento de fibras alimentares totais representa de 320 a $380 \%$.

Os teores de fibras alimentares solúveis variaram de 2,10 a 3,64 g. $100 \mathrm{~g}^{-1}$, e de fibras alimentares insolúveis variaram de 4,85 a 7,65 g. $100 \mathrm{~g}^{-1}$. Observou-se uma adequada distribuição entre os teores de fibras solúveis e insolúveis nos snacks, devido à combinação das diferentes farinhas. Danesi, Granato, Iwasa, Pinzon e Bolanho (2016) observaram que a farinha de laranja produzida nas mesmas condições desse trabalho apresentou 47,8 g. $100 \mathrm{~g}^{-1}$ de fibras insolúveis e $23,8 \mathrm{~g}$. $100 \mathrm{~g}^{-1}$ de fibras solúveis, enquanto a farinha de palmito pupunha apresentou $65,8 \mathrm{~g} .100 \mathrm{~g}^{-1}$ de fibras insolúveis e $35,1 \mathrm{~g}$. $100 \mathrm{~g}^{-1}$ de fibras solúveis, corroborando com os teores de fibras observados nos snacks.

Os snacks apresentaram valores energéticos de 346 a $355 \mathrm{kcal} .100 \mathrm{~g}^{-1}$. Na porção de $25 \mathrm{~g}$ o valor energético variou de 87 a $89 \mathrm{kcal}$. A porção do produto comercial apresentou valor energético superior, $99 \mathrm{kcal}$. Os valores energéticos dos snacks com Spirulina sp. desenvolvidos por Morsy et al. (2014) foram superiores aos deste estudo, $117 \mathrm{kcal}$. Estes valores energéticos superiores podem estar relacionados ao maior teor de lipídios nos snacks comerciais (7,2 g. $100 \mathrm{~g}^{-1}$ ) (Belive, 2021) e de Morsy et al. (2014) $\left(20\right.$ g. $\left.100 \mathrm{~g}^{-1}\right)$. 
Research, Society and Development, v. 10, n. 5, e41310515142, 2021

(CC BY 4.0) | ISSN 2525-3409 | DOI: http://dx.doi.org/10.33448/rsd-v10i5.15142

Tabela 2. Composição proximal, fenólica e atividade antioxidante dos snacks.

\begin{tabular}{|c|c|c|c|c|c|c|c|c|c|c|}
\hline \multirow{4}{*}{$\begin{array}{c}\text { Variáveis } \\
\text { Indepedentes }\end{array}$} & \multirow{4}{*}{$\begin{array}{c}\mathrm{X}_{1}(\mathrm{SP}) \\
\mathrm{X}_{2}(\mathrm{U})\end{array}$} & \multicolumn{7}{|c|}{ Formulações } & \multicolumn{2}{|c|}{ Análise estatística } \\
\hline & & \multirow{3}{*}{$\begin{array}{c}\mathrm{A} \\
-1(2,5) \\
-1(18)\end{array}$} & \multirow{3}{*}{$\begin{array}{c}\text { B } \\
+1(7,5) \\
-1(18)\end{array}$} & \multirow{3}{*}{$\begin{array}{c}\mathrm{C} \\
-1(2,5) \\
+1(26)\end{array}$} & \multirow{3}{*}{$\begin{array}{c}\mathrm{D} \\
+1(7,5) \\
+1(26)\end{array}$} & \multirow{3}{*}{$\begin{array}{c}\mathrm{E} \\
0(5,0) \\
0(22)\end{array}$} & \multirow{3}{*}{$\begin{array}{c}\mathrm{F} \\
0(5,0) \\
0(22)\end{array}$} & \multirow{3}{*}{$\begin{array}{c}\mathrm{G} \\
0(5,0) \\
0(22)\end{array}$} & & \\
\hline & & & & & & & & & & \\
\hline & & & & & & & & & p-valor ${ }^{1}$ & p-valor ${ }^{2}$ \\
\hline \multirow{8}{*}{$\begin{array}{c}\text { Composição } \\
\text { proximal }\end{array}$} & Umidade & $3,26 \pm 0,10^{c}$ & $4,15 \pm 0,16^{\mathrm{a}}$ & $4,01 \pm 0,13^{\mathrm{a}}$ & $3,60 \pm 0,11^{\mathrm{b}}$ & $3,53 \pm 0,23^{\mathrm{bc}}$ & $3,97 \pm 0,11^{\mathrm{a}}$ & $4,00 \pm 0,36^{\mathrm{a}}$ & 0,030 & 0,003 \\
\hline & Cinzas & $2,00 \pm 0,05^{\mathrm{a}}$ & $1,84 \pm 0,02^{\mathrm{c}}$ & $1,52 \pm 0,02^{\mathrm{e}}$ & $1,86 \pm 0,02^{\mathrm{b}}$ & $1,91 \pm 0,07^{\mathrm{bc}}$ & $1,73 \pm 0,03^{\mathrm{d}}$ & $1,88 \pm 0,03^{\mathrm{bc}}$ & 0,021 & $<0,001$ \\
\hline & Proteínas & $9,65 \pm 0,09^{f}$ & $12,14 \pm 0,10^{\mathrm{b}}$ & $10,03 \pm 0,18^{\mathrm{e}}$ & $12,40 \pm 0,10^{\mathrm{a}}$ & $11,38 \pm 0,13^{\mathrm{c}}$ & $11,34 \pm 0,20^{\mathrm{c}}$ & $10,88 \pm 0,10^{\mathrm{d}}$ & 0,797 & $<0,001$ \\
\hline & Lipídios & $0,31 \pm 0,04^{\mathrm{c}}$ & $0,37 \pm 0,01^{\mathrm{b}}$ & $0,41 \pm 0,06^{\mathrm{b}}$ & $0,79 \pm 0,06^{\mathrm{a}}$ & $0,15 \pm 0,01^{\mathrm{d}}$ & $0,19 \pm 0,00^{\mathrm{d}}$ & $0,08 \pm 0,01^{\mathrm{e}}$ & 0,158 & $<0,001$ \\
\hline & FAT & $9,75 \pm 0,26^{\mathrm{a}}$ & $8,57 \pm 0,09^{c}$ & $9,38 \pm 0,15^{\mathrm{ab}}$ & $8,49 \pm 0,29^{c}$ & $9,23 \pm 0,36^{\mathrm{b}}$ & $9,39 \pm 0,33^{\mathrm{ab}}$ & $9,45 \pm 0,26^{\mathrm{ab}}$ & 0,776 & $<0,001$ \\
\hline & FAS & $2,10 \pm 0,06^{\mathrm{e}}$ & $2,78 \pm 0,08^{\mathrm{d}}$ & $3,48 \pm 0,29^{\mathrm{a}}$ & $3,64 \pm 0,12^{\mathrm{a}}$ & $2,88 \pm 0,05^{\mathrm{cd}}$ & $3,13 \pm 0,03^{\mathrm{b}}$ & $3,07 \pm 0,02^{\mathrm{bc}}$ & 0,107 & $<0,001$ \\
\hline & FAI & $7,65 \pm 0,33^{\mathrm{a}}$ & $5,79 \pm 0,02^{\mathrm{c}}$ & $5,90 \pm 0,14^{\mathrm{bc}}$ & $4,85 \pm 0,41^{\mathrm{d}}$ & $6,35 \pm 0,31^{b}$ & $6,26 \pm 0,31^{b c}$ & $6,39 \pm 0,24^{b}$ & 0,518 & $<0,001$ \\
\hline & $\mathrm{CHO}$ & $75,04 \pm 0,24^{\mathrm{a}}$ & $72,93 \pm 0,12^{\mathrm{c}}$ & $74,64 \pm 0,28^{\mathrm{a}}$ & $72,86 \pm 0,43^{c}$ & $73,79 \pm 0,49^{b}$ & $73,38 \pm 0,52^{\mathrm{bc}}$ & $73,70 \pm 0,28^{b}$ & 0,191 & $<0,001$ \\
\hline \multirow{3}{*}{$\begin{array}{c}\text { Compostos } \\
\text { fenólicos e } \\
\text { Atividade } \\
\text { antioxidante }\end{array}$} & AA & $84,8 \pm 0,9^{\mathrm{a}}$ & $78,0 \pm 3,3^{\mathrm{b}}$ & $78,4 \pm 0,7^{b}$ & $81,5 \pm 5,1^{\mathrm{ab}}$ & $85,0 \pm 0,3^{\mathrm{a}}$ & $82,7 \pm 2,3^{\mathrm{ab}}$ & $82,4 \pm 3,2^{\mathrm{ab}}$ & 0,005 & $<0,001$ \\
\hline & CRFC & $44,54 \pm 0,62^{\mathrm{ab}}$ & $47,99 \pm 0,44^{\mathrm{a}}$ & $39,95 \pm 4,48^{c}$ & $48,10 \pm 2,66^{\mathrm{a}}$ & $46,14 \pm 3,25^{\mathrm{ab}}$ & $42,25 \pm 2,53^{\mathrm{bc}}$ & $42,23 \pm 1,09^{\mathrm{bc}}$ & 0,033 & 0,003 \\
\hline & CFT & $3,26 \pm 0,04^{\mathrm{c}}$ & $4,54 \pm 0,08^{\mathrm{a}}$ & $2,44 \pm 0,06^{\mathrm{e}}$ & $3,42 \pm 0,16^{\mathrm{c}}$ & $4,08 \pm 0,13^{\mathrm{b}}$ & $2,68 \pm 0,19^{d}$ & $2,84 \pm 0,09^{\mathrm{d}}$ & 0,120 & $<0,001$ \\
\hline
\end{tabular}

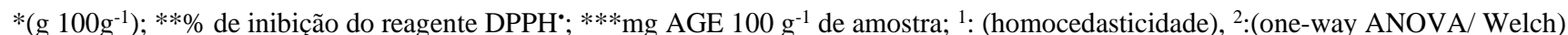

Letras distintas na mesma linha indicam diferença estatística significativa ao nível de $5 \%$ pelo teste de Fisher; Na linha das variáveis independentes, $\mathrm{X}_{1}$ e $\mathrm{X}_{2}$ representam as variáveis codificadas e entre parênteses o valor da variável real, Spirulina platensis $(\mathrm{SP})$ e umidade de alimentação (U), respectivamente; FAT = fibra alimentar total, FAS = fibra alimentar solúvel, FAI = fibra alimentar insolúvel; $\mathrm{AA}=$ Atividade antioxidante $; \mathrm{CRCF}=$ Capacidade redutora de Folin-Ciocalteu; $\mathrm{CFT}=$ Capacidade fenólica total

Fonte: Autores. 
A farinha de arroz (FA) apresentou $7 \%$ de inibição de DPPH• para atividade antioxidante e $47 \mathrm{mg}^{\mathrm{AGE}} 100 \mathrm{~g}^{-1}$ nos valores de CRFC. Houve redução da AA e CRFC após a extrusão da FA isolada, onde os valores médios foram 4 \% de inibição de DPPH• e 29 mg AGE. $100 \mathrm{~g}^{-1}$ e, respectivamente. Os valores de CFT não foram detectados. A farinha de palmito pupunha apresentou 10 \% de inibição de DPPH• e 253 mg AGE. $100 \mathrm{~g}^{-1}$ nos valores de AA e CRFC, respectivamente. A farinha de laranja (FL) continha 75\% de inibição de DPPH•, 347 mg AGE. $100 \mathrm{~g} \mathrm{~g}^{-1}$, e 96 mg AGE. $100 \mathrm{~g}^{-1}$, de AA, CRFC e CFT, respectivamente. A S. platensis apresentou $1222 \mathrm{mg}$ AGE. $100 \mathrm{~g}^{-1}$ na CRFC e $576 \mathrm{mg}$ AGE. $100 \mathrm{~g}^{-1}$ de CFT. A partir dos dados apresentados na Tabela 2, podemos constatar que a substituição parcial de farinha de arroz por subprodutos de laranja, de palmito pupunha e $S$. platensis nas formulações dos snacks promoveu aumento da AA em mais de $1000 \%$.

$\mathrm{Na}$ análise comparativa entre as formulações de maior umidade de alimentação (U), 26\%, o incremento de SP aumentou a CRFC, este comportamento pode ser observado entre as amostras C e D (Tabela 2). Marco et al. (2014) estudaram a incorporação de S. platensis em macarrão. Os autores observaram que a adição de S. platensis em todos os níveis estudados exibiu maior atividade antioxidante que a amostra controle de macarrão. A incorporação de S. platensis nas formulaçõesdos snacks extrusados possibilitou o aumento do valor nutricional, bem como o aumento do conteúdo proteico de alto valor biológico e de compostos bioativos.

A metodologia de superfície de resposta (MSR) foi aplicada para avaliar os efeitos da S. platensis e umidade de alimentação na composição proximal, fenólica e atividade antioxidante, e os resultados foram modelados matematicamente. Na Figura 1A, o diagrama de Pareto demonstra que apenas SP teve efeito significativamente positivo $(p \leq 0,20)$ sobre o teor de proteínas. Na Figura 1B, observa-se que quanto maior a quantidade de SP adicionada à formulação maior o teor proteico dos snacks. Os dados experimentais do teor de proteínas dos snacks foram adequadamente ajustados $\left(\mathrm{p}_{\text {falta de ajuste }}=0,671, \mathrm{R}^{2}=0,952, \mathrm{R}^{2}\right.$ ajustado $=0,942$, p pormalidade dos resíduos $=0,152$ ), o modelo de regressão múltipla proposto foi capaz de explicar $94 \%$ da variabilidade dos dados.

Figura 1. Efeito do conteúdo de S. platensis (SP) e umidade de alimentação (U) no teor de proteínas dos snacks. A) Diagrama de Pareto em função do teste $t$-Student $(p \leq 0,20)$; B) superfície de contorno para a variável dependente: Proteínas
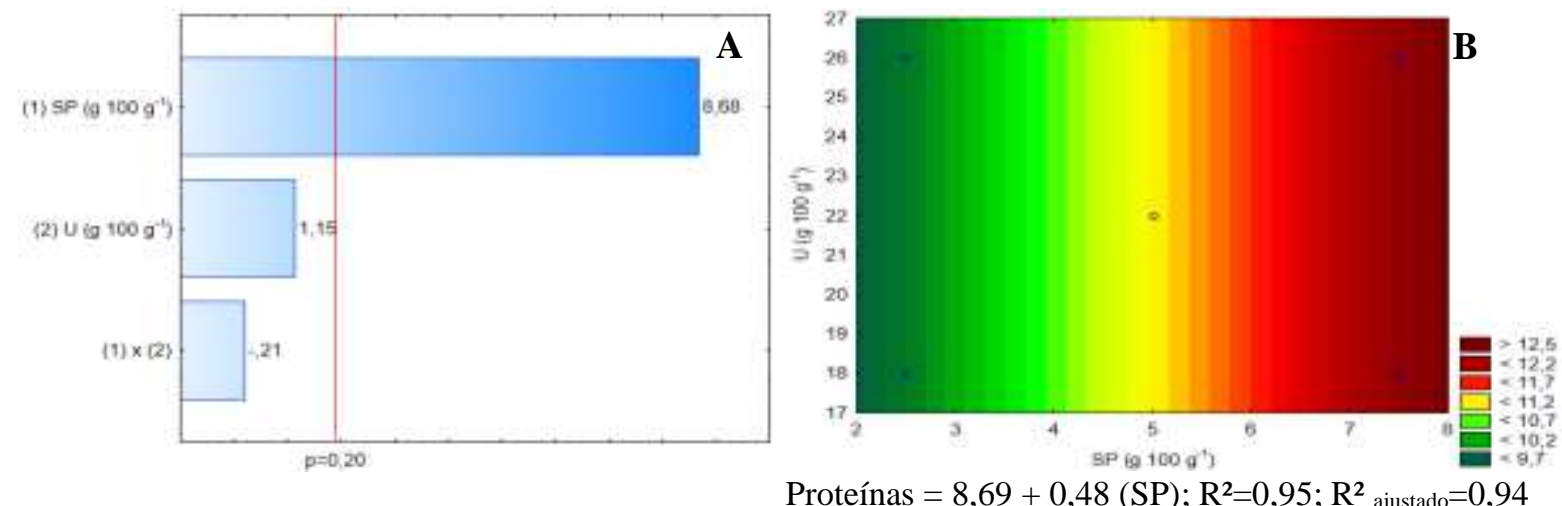

Proteínas $=8,69+0,48(\mathrm{SP}) ; \mathrm{R}^{2}=0,95 ; \mathrm{R}^{2}$ ajustado $=0,94$

Fonte: Autores.

Na análise dos efeitos da SP e U sobre a atividade antioxidante dos snacks, somente a interação das variáveis independentes promoveu efeito positivo, Figura 2A. Sobre a CRFC, a SP promoveu efeito positivo (Figura 2B), e sobre o teor de CFT nenhuma das variáveis promoveu efeito significativo (Figura 2C). Os modelos de regressão para AA, CRFC e CFT não foram preditivos para descrever os dados experimentais (dados não apresentados). 
Figura 2. Efeito do conteúdo de S. platensis (SP) e umidade de alimentação (U) na atividade antioxidante e composição fenólica dos snacks. A) Diagrama de Pareto de capacidade antioxidante pela inibição do reagente DPPH`; B) Diagrama de Pareto da capacidade redutora do reagente Folin-Ciocalteu, e C) Diagrama de Pareto para compostos fenólicos totais.

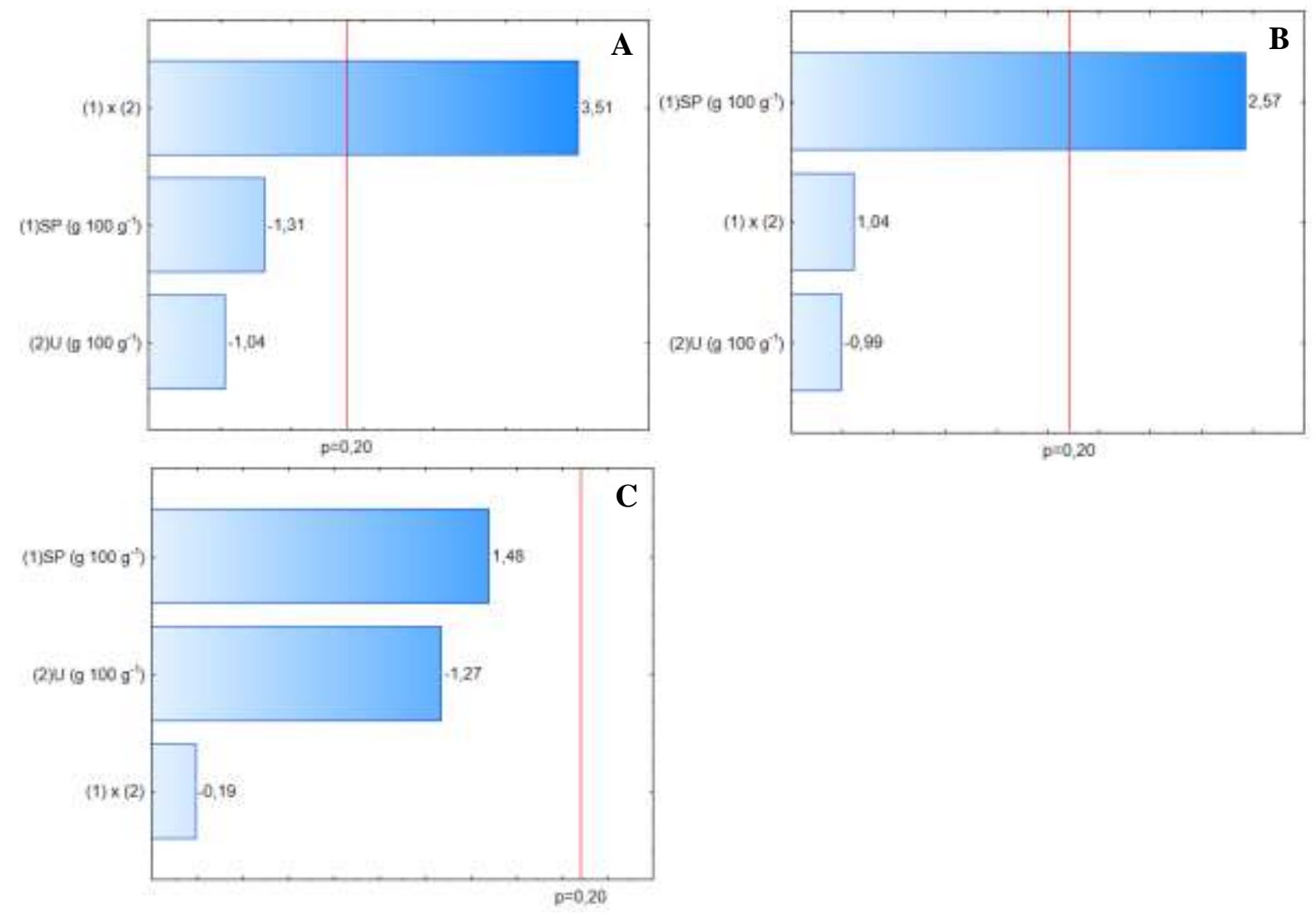

Fonte: Autores.

\section{Parâmetros tecnológicos dos snacks}

Os resultados das caracterizações tecnológicas dos snacks elaborados encontram-se expressos na Tabela 3. Os valores médios dos parâmetros tecnológicos, propriedades mecânicas e cor instrumental apresentaram diferença significativa $(p \leq 0,05)$.

O índice de expansão variou de 170 a $254 \%$, e a densidade aparente de 323 a 476 g. L ${ }^{-1}$, Tabela 3. Neste estudo, a umidade de alimentação não influenciou o índice de expansão (IE), mas o aumento de U ocasionou snacks com maiores valores de densidade aparente (DA). A S. platensis, em todos os níveis testados não demonstrou influência sobre IE e DA. No estudo conduzido por Lucas et al. (2017) em snacks de milho e arroz com diferentes níveis de S. platensis $(0,4$ a 2,6 \%) apenas a umidade de alimentação, que variou de 15 a $21 \%$, promoveu efeito sobre IE e DA, os autores obtiveram IE de 250 a $450 \%$ e DA de 100 a 430 g. L ${ }^{-1}$.

Os valores de densidade aparente (DA) (Tabela 3) foram próximos aos observados por Ding, Ainsworth, Tucker e Marson (2005) em snacks de arroz (100 a 430 g. L L $^{-1}$ ) e Alam et al. (2016) em snacks de arroz com substituição por proteínas (farinha de soja) e fibras (subprodutos de cenoura e couve-flor), em quantidades de 15 a 35 g.100 g-1, obtendo valores de DA de 112 a 365 g. $\mathrm{L}^{-1}$. 
Research, Society and Development, v. 10, n. 5, e41310515142, 2021

(CC BY 4.0) | ISSN 2525-3409 | DOI: http://dx.doi.org/10.33448/rsd-v10i5.15142

Tabela 3. Parâmetros tecnológicos, Aw, propriedades mecânicas e cor instrumental dos snacks extrusados com subprodutos agroindustriais e S. platensis

\begin{tabular}{|c|c|c|c|c|c|c|c|c|c|c|}
\hline \multirow{4}{*}{$\begin{array}{c}\text { Variáveis } \\
\text { independentes }\end{array}$} & \multirow{4}{*}{$\begin{array}{l}\mathrm{X}_{1}(\mathrm{SP}) \dagger \\
\mathrm{X}_{2}(\mathrm{U}) \dagger\end{array}$} & \multicolumn{7}{|c|}{ Formulações } & \multirow{2}{*}{\multicolumn{2}{|c|}{ Análise estatística }} \\
\hline & & \multirow{2}{*}{$\frac{A}{-1(2,5)}$} & \multirow{2}{*}{$\begin{array}{c}\mathrm{B} \\
+1(7,5)\end{array}$} & \multirow{2}{*}{$\frac{C}{-1(2,5)}$} & \multirow{3}{*}{$\begin{array}{c}\mathrm{D} \\
+1(7,5) \\
+1(26)\end{array}$} & \multirow{3}{*}{$\begin{array}{c}\mathrm{E} \\
0(5,0) \\
0(22)\end{array}$} & \multirow{3}{*}{$\begin{array}{c}\mathrm{F} \\
0(5,0) \\
0(22)\end{array}$} & \multirow{3}{*}{$\begin{array}{c}\mathrm{G} \\
0(5,0) \\
0(22)\end{array}$} & & \\
\hline & & & & & & & & & p-valor ${ }^{1}$ & p-valor ${ }^{2}$ \\
\hline & & & $-1(18)$ & $+1(26)$ & & & & & & \\
\hline & $\operatorname{IE~}(\%) \ddagger$ & $211 \pm 11^{b}$ & $254 \pm 15^{\mathrm{a}}$ & $216 \pm 17^{c}$ & $170 \pm 14^{\mathrm{e}}$ & $189 \pm 16^{\mathrm{d}}$ & $254 \pm 12^{\mathrm{a}}$ & $239 \pm 11^{\mathrm{b}}$ & 0,671 & $<0,001$ \\
\hline \multirow{5}{*}{$\begin{array}{l}\text { Parâmetros } \\
\text { tecnológicos }\end{array}$} & DA $\left(\mathrm{g} \cdot \mathrm{L}^{-1}\right) \ddagger$ & $329 \pm 10^{\mathrm{d}}$ & $323 \pm 10^{\mathrm{d}}$ & $412 \pm 12^{b}$ & $476 \pm 39^{a}$ & $407 \pm 24^{b}$ & $465 \pm 12^{c}$ & $378 \pm 14^{c}$ & 0,008 & $<0,001$ \\
\hline & ISA $\left(\mathrm{g} .100 \mathrm{~g}^{-1}\right) \ddagger$ & $8,58 \pm 0,20^{\mathrm{de}}$ & $11,92 \pm 0,52^{\mathrm{a}}$ & $9,81 \pm 0,07^{\mathrm{c}}$ & $10,30 \pm 0,21^{\mathrm{bc}}$ & $10,47 \pm 0,14^{\mathrm{b}}$ & $8,93 \pm 0,52^{\mathrm{d}}$ & $8,29 \pm 0,25^{\mathrm{e}}$ & 0,016 & $<0,001$ \\
\hline & IAA $\left(\right.$ g gel. $\left.\mathrm{g}^{-1}\right) \dagger$ & $6,35 \pm 0,08^{\mathrm{a}}$ & $5,66 \pm 0,04^{\mathrm{c}}$ & $5,76 \pm 0,04^{\mathrm{c}}$ & $4,76 \pm 0,19^{d}$ & $4,70 \pm 0,04^{\mathrm{d}}$ & $5,93 \pm 0,07^{\mathrm{b}}$ & $4,63 \pm 0,12^{\mathrm{d}}$ & 0,023 & $<0,001$ \\
\hline & IAO $\left(\right.$ g gel. $\left.^{-1}\right) \ddagger$ & $1,63 \pm 0,03^{\text {bcd }}$ & $1,66 \pm 0,06^{\mathrm{bc}}$ & $1,62 \pm 0,06^{\mathrm{cd}}$ & $1,58 \pm 0,01^{\mathrm{d}}$ & $1,70 \pm 0,01^{\mathrm{b}}$ & $1,61 \pm 0,03^{\mathrm{cd}}$ & $1,82 \pm 0,05^{\mathrm{a}}$ & 0,283 & $<0,001$ \\
\hline & Aw & $0,13 \pm 0,00^{\mathrm{d}}$ & $0,16 \pm 0,00^{\mathrm{b}}$ & $0,14 \pm 0,00^{\mathrm{d}}$ & $0,17 \pm 0,00^{\mathrm{a}}$ & $0,15 \pm 0,00^{\mathrm{c}}$ & $0,15 \pm 0,00^{\mathrm{c}}$ & $0,17 \pm 0,00^{\mathrm{b}}$ & 0,745 & $<0,001$ \\
\hline \multirow{2}{*}{$\begin{array}{l}\text { Propriedades } \\
\text { mecânicas }\end{array}$} & $\begin{array}{l}\text { Crocância } \\
\left(\mathrm{n}^{\circ} \text { de picos }\right)\end{array}$ & $28 \pm 3^{a}$ & $25 \pm 1^{b}$ & $20 \pm 1^{c}$ & $17 \pm 1^{\mathrm{d}}$ & $14 \pm 1^{\mathrm{e}}$ & $20 \pm 1^{c}$ & $17 \pm 1^{\mathrm{d}}$ & 0,076 & $<0,001$ \\
\hline & Dureza $(\mathrm{N})$ & $16,5 \pm 1,1^{\mathrm{a}}$ & $0,8 \pm 0,1^{\mathrm{d}}$ & $10,7 \pm 0,7^{b}$ & $5,3 \pm 0,5^{\mathrm{c}}$ & $7,1 \pm 2,4^{\mathrm{c}}$ & $2,7 \pm 0,3^{\mathrm{d}}$ & $6,4 \pm 1,5^{\mathrm{c}}$ & 0,002 & $<0,001$ \\
\hline \multirow{4}{*}{ Cor instrumental } & $L^{*}$ & $30,14 \pm 0,92^{\mathrm{a}}$ & $23,80 \pm 0,42^{\mathrm{b}}$ & $23,79 \pm 0,47^{b}$ & $15,90 \pm 0,81^{\mathrm{f}}$ & $20,88 \pm 0,63^{\mathrm{d}}$ & $20,34 \pm 0,28^{\mathrm{e}}$ & $22,30 \pm 0,26^{c}$ & 0,002 & $<0,001$ \\
\hline & $a^{*}$ & $1,42 \pm 0,14^{\mathrm{a}}$ & $0,86 \pm 0,14^{\mathrm{c}}$ & $1,18 \pm 0,06^{\mathrm{b}}$ & $0,10 \pm 0,06^{\mathrm{e}}$ & $0,43 \pm 0,10^{\mathrm{d}}$ & $0,91 \pm 0,09^{c}$ & $0,87 \pm 0,12^{\mathrm{c}}$ & 0,036 & $<0,001$ \\
\hline & $b^{*}$ & $13,82 \pm 0,64^{\mathrm{a}}$ & $9,94 \pm 0,53^{\mathrm{b}}$ & $10,17 \pm 0,31^{\mathrm{b}}$ & $3,46 \pm 0,67^{e}$ & $7,43 \pm 0,44^{\mathrm{d}}$ & $7,67 \pm 0,33^{\mathrm{d}}$ & $8,79 \pm 0,45^{\mathrm{c}}$ & 0,037 & $<0,001$ \\
\hline & $\Delta \mathrm{E} t$ & $36,42 \pm 0,90^{c}$ & $32,90 \pm 0,54^{\mathrm{f}}$ & $38,90 \pm 0,40^{\mathrm{a}}$ & $32,60 \pm 1,22^{\mathrm{f}}$ & $37,75 \pm 0,64^{\mathrm{b}}$ & $34,93 \pm 0,56^{\mathrm{d}}$ & $34,04 \pm 0,44^{\mathrm{e}}$ & 0,020 & $<0,001$ \\
\hline
\end{tabular}

†Variáveis independentes codificadas $\left(\mathrm{X}_{1}\right.$ e $\left.\mathrm{X}_{2}\right)$, e entre parênteses variáveis independentes reais, onde SP corresponde à S. platensis e U à umidade em g.100g-1

† Índice de expansão (IE\%); Densidade Aparente (DA - g. L $\mathrm{L}^{-1}$ ); Índice de solubilidade em água (ISA - g. $100 \mathrm{~g}^{-1}$ ); Índice de absorção de água (IAA - g gel. g $\mathrm{g}^{-1}$ ); Índice de absorção de óleo (IAO g gel. $\left.\mathrm{g}^{-1}\right)$ e Atividade de água $(\mathrm{Aw}) ; * * \Delta \mathrm{E}$, diferença de cor entre as formulações e os snacks

: homocedasticidade; ${ }^{2}$ : one-way ANOVA/ Welch

ANOVA (a partir de dados homocedásticos) quando as diferentes formulações são comparadas; NOTAS: Valores das variáveis dependentes expressos em média e desvio padrão; Letras distintas na mesma linha indicam diferença estatística significativa ao nível de 5\% pelo teste de Fisher

Fonte: Autores. 
As fibras alientares contidas na farinha mista de subprodutos utilizada nas formulações podem ter contribuído para a redução do IE e aumento de DA dos snacks mais do que as variáveis independentes estudadas. Produtos extrusados enriquecidos em fibras tendem a aumentar a densidade aparente, pois estas impedem a completa gelatinização do amido e formação de bolhas de ar, gerando produtos mais densos (Steel, Leoro, Schimiele, ferreira \&Chang, 2012; Brenan et al., 2008). A redução do IE tem sido relatada em produtos extrusados com a adição de fibras alimentares na formulação (Alam et al., 2016; Selani et al., 2014; Larrea et al., 2005).

A incorporação de substâncias que impedem a completa gelatinização do amido, como fibras e proteínas, geram produtos extrusados com valores reduzidos de índice de solubilidade em água (ISA) (Harper \&clark, 1979). Assim, os valores de ISA neste estudo de 8,29 a 11,92 g.100 g $\mathrm{g}^{-1}$ foram menores que os observados no estudo de Ding et al. (2005) de 21,52 a 32,70 g.100 g ${ }^{-1}$, em extrusados exclusivamente de arroz.

O índice de absorção de água (IAA) mede a quantidade de água absorvida pelos constituintes e pode ser usado para medir o grau de gelatinização. A redução da umidade de alimentação tem a capacidade de aumentar o IAA dos produtos extrusados a partir de farinha de arroz (Ding et al., 2005). Este efeito foi observado neste estudo e pode ser observado na Tabela 3 entre as formulações A $\left(6,35 \mathrm{~g}\right.$ gel. $\left.\mathrm{g}^{-1}\right)$ e C $\left(5,76 \mathrm{~g}\right.$ gel. $\left.\mathrm{g}^{-1}\right)$, e entre as formulações B $\left(5,66 \mathrm{~g}\right.$ gel. $\left.\mathrm{g}^{-1}\right)$ e D $\left(4,76 \mathrm{~g}\right.$ gel. $\left.\mathrm{g}^{-1}\right)$.

O índice de absorção de óleo (IAO) é um fator importante a ser conhecido no desenvolvimento de novos produtos alimentícios e determinação de estabilidade de armazenamento, para evitar rancidez oxidativa e o sabor característico. As condições de extrusão podem causar alterações nas proteínas, resultando em desnaturação, alteração e aumento da quantidade de sítios hidrofóbicos que reagem com os lipídios (Fiorda et al., 2015). Os valores obtidos neste estudo foram menores que em outros estudos feitos por Deshpande \& Poshadri (2011) e Fiorda et al. (2015), favorecendo a estabilidade ao armazenamento. Os menores valores de IAO deste trabalho podem estar relacionados ao elevado teor de proteínas, presente na S. platensis e sua desnaturação durante a extrusão.

Produtos obtidos por extrusão apresentam baixa atividade de água (Aw), de 0,1 a 0,4. Em alimentos secos, como snacks extrusados, a baixa atividade de água é uma vantagem em relação à estabilidade contra o crescimento microbiano e determina o prazo de vida útil (Harper \& Clark, 1979). Apenas a variável SP apresentou efeito significativamente positivo ( $\mathrm{p} \leq 0,20)$ sobre a Aw. As proteínas se associam mais fortemente com a água (Lucas et al., 2017), desse modo, o aumento de SP nas formulações pode ter impedido a perda de água nos processos de extrusão e secagem, ocasionando uma relação positiva de SP e Aw.

As variáveis independentes, SP e U, não promoveram efeito significativo ( $p>0,20)$ sobre o índice de expansão (IE), o índice de solubilidade em água (ISA) e o índice de absorção de água (IAA). No entanto, o efeito foi significativo (p $\leq 0,20$ ) para densidade aparente (DA) e atividade de água (Aw), representados pelos diagramas de Pareto, na Figura 3. Entre os efeitos estudados no modelo de regressão linear, constata-se que apenas SP está associada ao aumento da Aw. Embora a umidade tenha promovido efeito significativo sobre DA a análise de regressão múltipla mostrou que o modelo não foi significativo (p=0,424), inviabilizando sua aplicação para fins preditivos (dados não apresentados). Na Figura 4, podem-se visualizar as superfícies de contorno para Aw e DA. 
Figura 3. Diagrama de Pareto em relação ao efeito do conteúdo de S. platensis (SP) e umidade de alimentação das formulações (U) nos valores de: A) Índice de Expansão (IE); B) Densidade Aparente (DA); C) Índice de solubilidade em água (ISA); D) Índice de absorção em água (IAA); E) Índice de absorção em óleo (IAO) e F) Atividade de água (Aw) dos snacks.
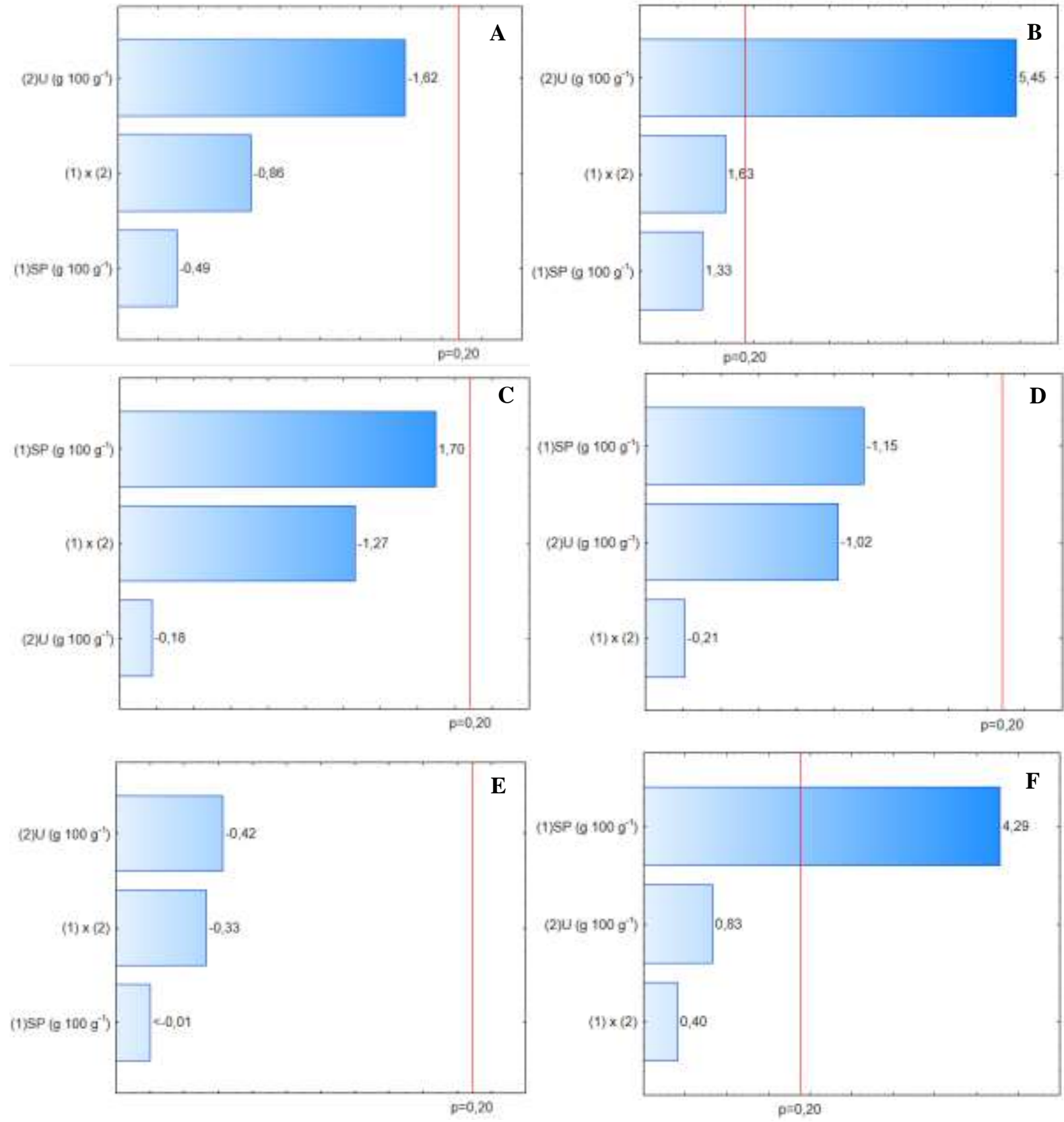

Fonte: Autores. 
Figura 4. Superfície de contorno do efeito do conteúdo de S. platensis (SP) e umidade de alimentação (U) em relação aos valores de: A) atividade de água (Aw) e B) Densidade aparente (DA) dos snacks.

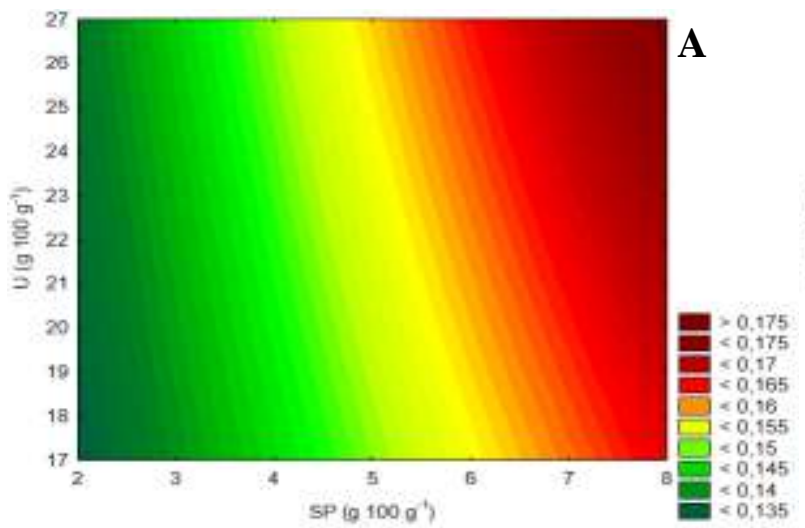

$\mathrm{Aw}=0,12+0,01(\mathrm{SP}) ; \mathrm{R}^{2}=0,82 ; \mathrm{R}^{2}{ }_{\text {ajustado }}=0,78$

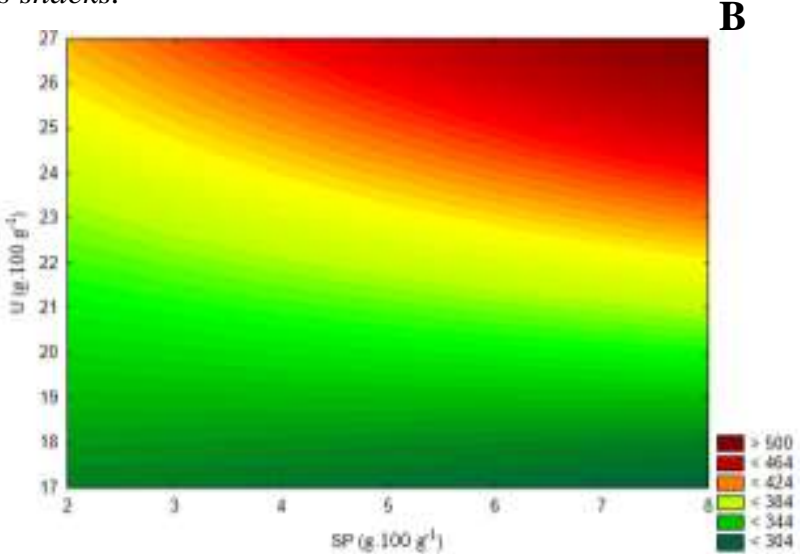

$\mathrm{DA}=59,84+14,74(\mathrm{U}) \mathrm{R}^{2}=0,82 ; \mathrm{R}^{2}$ ajustado $=0,79$

Fonte: Autores.

A crocância é dada pela força requerida para o probe atravessar o extrusado (DING et al., 2005). Neste estudo a crocância variou de 14 a 28 picos. Na Figura 5A observou-se efeito significativamente negativo $(p \leq 0,20)$ de U sobre crocância, ou seja, para menores valores de U houve aumento da crocância. As amostras A e B, com menores teores de umidade de alimentação nas formulações (18 g.100 g ${ }^{-1}$ ) apresentaram maior crocância. Ding et al. (2005) também observaram efeito negativo da umidade de alimentação sobre a crocância em snacks de arroz.

A dureza é a força máxima requerida para romper a amostra (Joshi et al., 2014). A dureza dos snacks variaram de 0,8 a 16,5 N. Na Figura 5B, o gráfico de Pareto pode ser observado enfatizando que apenas a variável SP promoveu efeito significativamente negativo $(\mathrm{p} \leq 0,20)$ sobre dureza. Este comportamento pode ser observado nas amostras com umidade de alimentação iguais e concentração de SP diferentes (Tabela 3). O aumento de S. platensis nas formulações associada à redução do amido, conferiu redução de dureza nos snacks, como pode ser visto entre as amostras A e B, e entre as amostras C e D, na Tabela 3. O maior valor de dureza foi observado na amostra A, com menor concentração de SP e o menor valor de dureza na amostra B, com maior concentração de SP. Os modelos de regressão múltipla para crocância e dureza foram significativos, mas não foram adequados, tornando inviável sua utilização para fins preditivos (dados não apresentados).

Figura 5. Efeito do conteúdo de $S$. platensis (SP) e umidade de alimentação (U) sobre as propriedades mecânicas dos snacks. A) Crocância; B) Dureza.

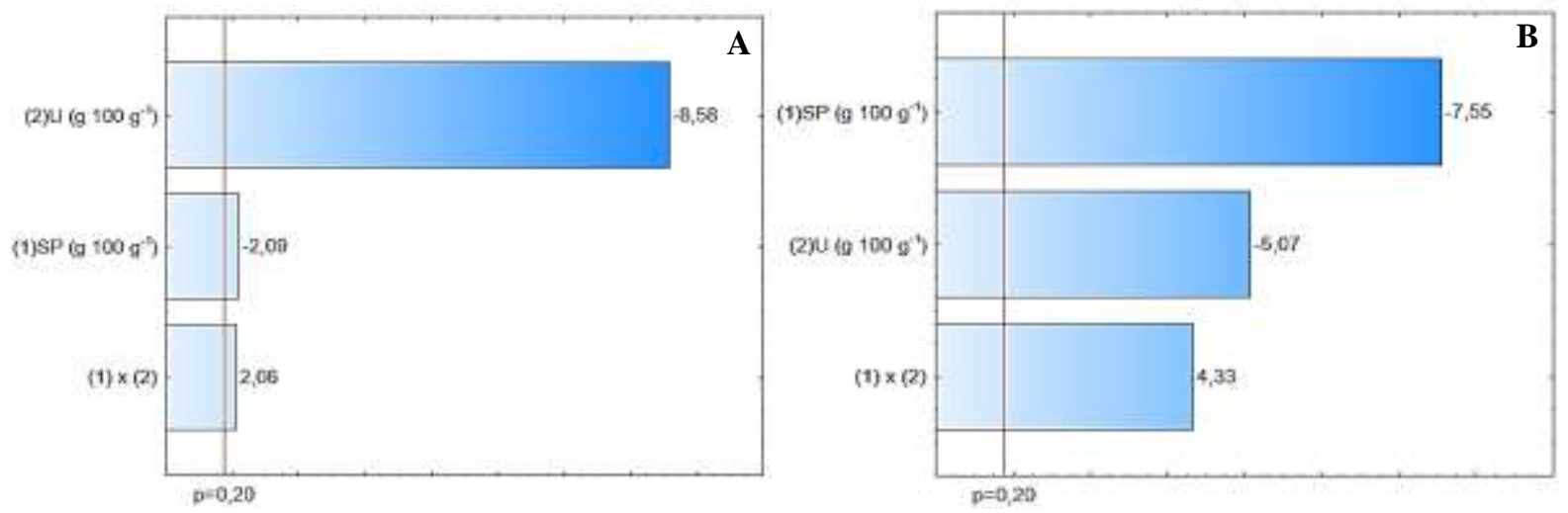

Fonte: Autores.

Na Figura 6 podem-se observar as imagens da secção transversal dos snacks desenvolvidos, nota-se a diferença de 
luminosidade, principalmente, entre as amostras A e D. O parâmetro $L^{*}$ (luminosidade) variou, em média, de 15,90 a 30,14 (Tabela 3). Na Figura 7 os diagramas de Pareto representam os efeitos das variáveis SP e U sobre os parâmetros de cor instrumental $L^{*}, a^{*}$, $b^{*}$ e $\Delta \mathrm{E}$. As variáveis independentes, SP e U, promoveram efeitos significativamente negativos $(\mathrm{p} \leq 0,20)$ sobre o parâmetro $L^{*}$, Figura 7A, ou seja, a menor umidade e adição de SP geraram snacks mais claros. Outros autores também observaram o efeito negativo de SP sobre luminosidade de snacks contendo S. platensis (Lucas et al., 2017; Tanska et al., 2017; Joshi et al., 2014).

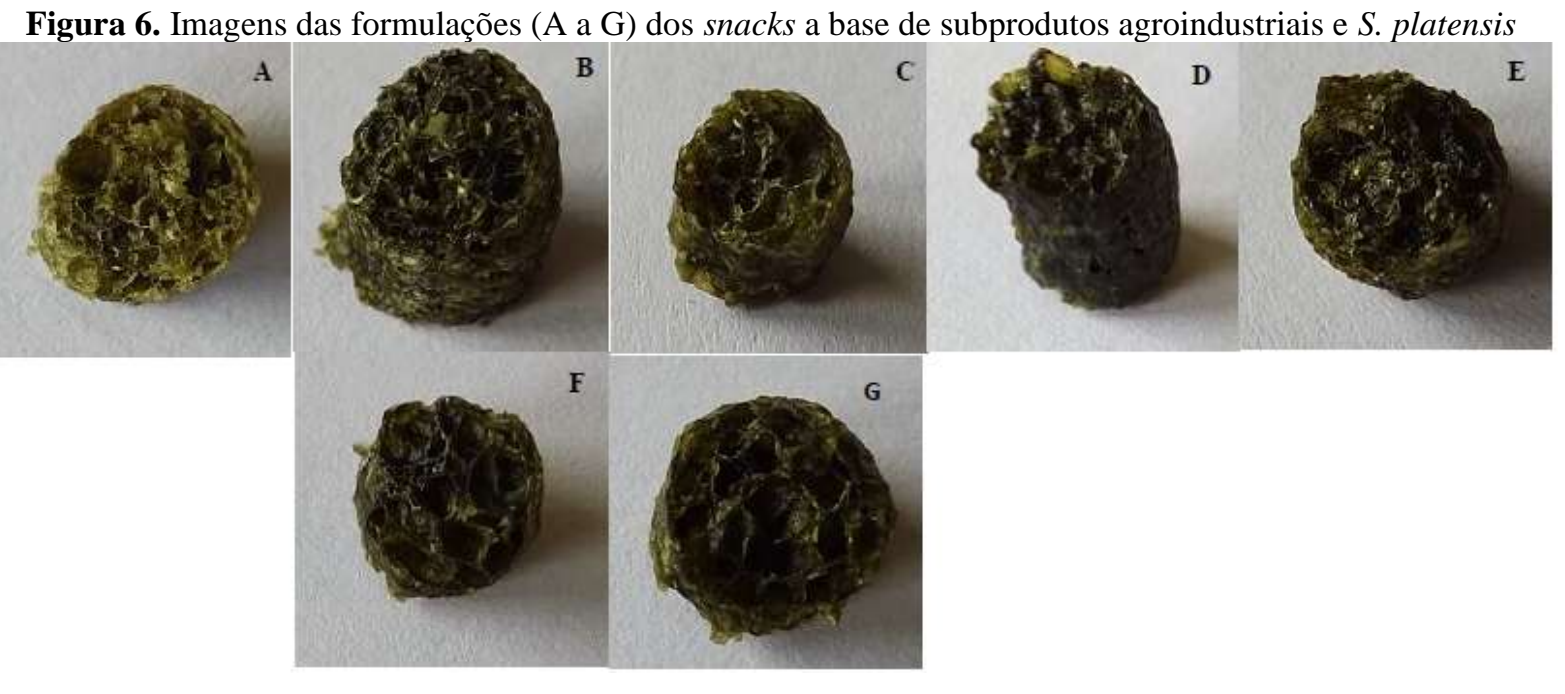

Fonte: Autores.

As médias dos valores de $a^{*}$ para os snacks variaram de 0,10 a 1,42 (Tabela 3). Apenas SP promoveu efeito significativamente negativo $(\mathrm{p} \leq 0,20)$ sobre o parâmetro $a^{*}$, Figura $7 \mathrm{~B}$, ou seja, quanto menores os valores de $\mathrm{SP}$, maior o valor do parâmetro a*. Valores similares foram observados por Lucas et al. (2017) no desenvolvimento de snacks de milho, arroz integral e S. platensis. As médias dos valores de $b^{*}$ para os snacks variaram de 3,46 a 13,82 (Tabela 3), indicam tendência ao amarelo. O efeito de SP ou U sobre o parâmetro $b^{*}$ foi significativamente negativo $(\mathrm{p} \leq 0,20)$, Figura $7 \mathrm{C}$.

Os valores médios de variação de cor entre formulações e snacks $(\Delta \mathrm{E})$ foram de 32,90 a 38,90 (Tabela 3 ). O efeito de SP sobre $\Delta \mathrm{E}$ foi significativamente negativo $(\mathrm{p} \leq 0,20)$, Figura $7 \mathrm{D}$, desse modo, a menor adição de SP nas formulações promoveu maior variação de cor $(\Delta \mathrm{E})$. Os valores de $\Delta \mathrm{E}$ observados por Lucas et al. (2017), foram de 26,15 a 32,55, mas diferentemente deste trabalho, o aumento de SP tendeu a aumentar $\Delta \mathrm{E}$. 
Figura 7. Diagrama de Pareto em relação ao efeito do conteúdo de S. platensis (SP) e umidade de alimentação (U) sobre os parâmetros colorimétricos. A) Parâmetro L*; B) Parâmetro a*; C) Parâmetro b*; D) Diferença de cor $(\Delta E)$.
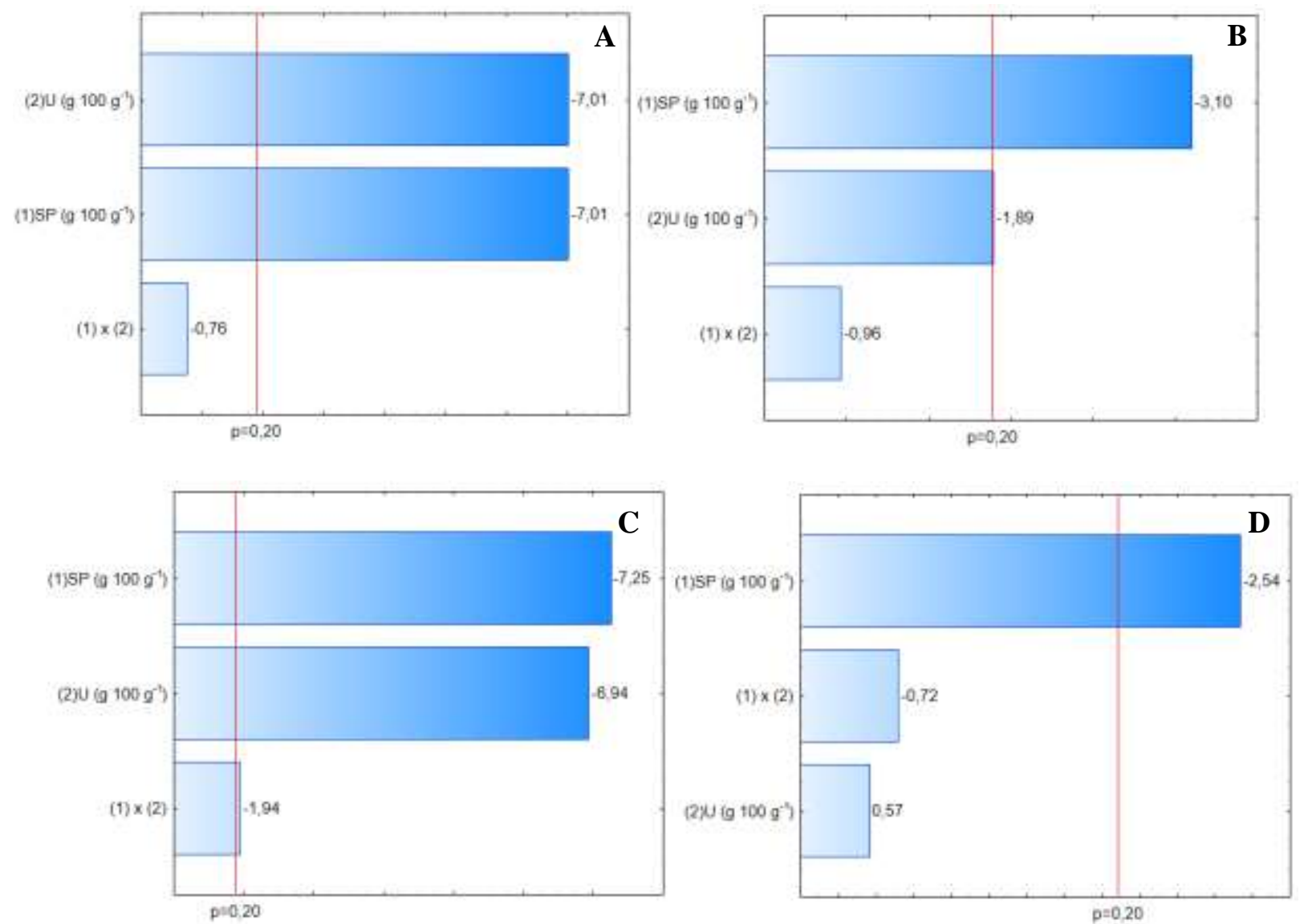

Fonte: Autores.

$\mathrm{Na}$ análise de regressão múltipla dos parâmetros de cor instrumental, os modelos foram bem ajustados, mas somente o modelo de regressão linear para o parâmetro $L^{*}$ consegue explicar $85 \%$ da variância, enquanto para $a^{*}, b^{*}$, e $\Delta \mathrm{E}$, os modelos não podem ser empregados para fins preditivos. Na Figura 8 o gráfico de contorno mostra os efeitos de U e SP sobre o parâmetro $L^{*}$, evidenciando o efeito negativo, ou seja, quanto menor SP ou U, maior esse valor.

Figura 8. Gráfico de contorno em relação ao efeito do conteúdo de S. platensis (SP) e umidade de alimentação (U) sobre cor instrumental dos snacks, parâmetro L*

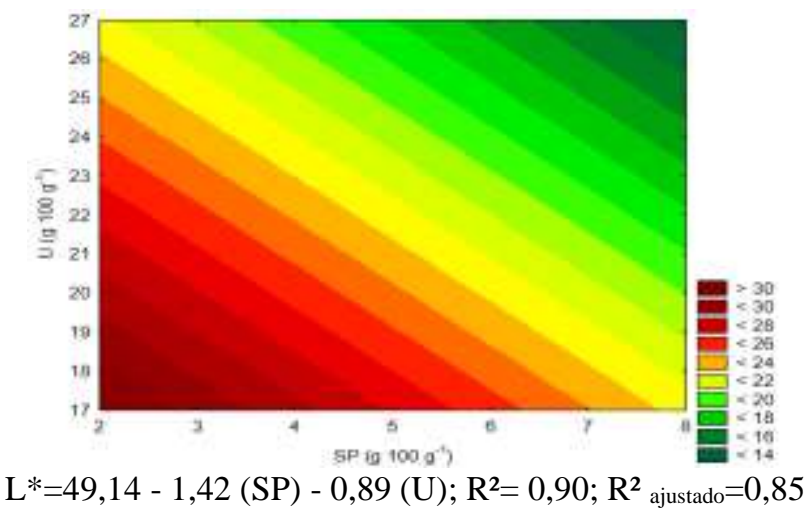

Fonte: Autores. 


\section{Análise sensorial}

As formulações apresentaram ausência de coliformes $45^{\circ} \mathrm{C}$ e Salmonella. Os resultados obtidos na análise sensorial estão dispostos na Tabela 4. As notas médias tiveram diferença significativa $(\mathrm{p} \leq 0,05)$, exceto para o sabor $(\mathrm{p}>0,05)$.

A aparência de um alimento é um dos fatores que define a qualidade, sendo a primeira impressão que o consumidor tem do produto. Os produtos extrusados costumam ter melhor aceitação com cores menos intensas (Fradique et al., 2010; Harper \& Clark, 1979). A aparência de extrusados pode estar relacionada ao índice de expansão, geralmente, produtos com IE mais elevados são preferidos pelos consumidores (Brennan, Desbyshire, Tiwari \& Brennan, 2013).

Nas Figuras 9A a 9E, os gráficos de Pareto representam os efeitos de SP e U sobre os atributos sensoriais, sendo que Figura 9A representa aparência, 9B cor, 9C odor, 9D textura e 9E impressão global. As variáveis SP e U promoveram efeito negativo $(p \leq 0,20)$ sobre os atributos aparência, cor e impressão global. Enquanto, para os atributos odor e textura, apenas U teve efeito negativo.

O aumento de SP nas formulações ocasionou queda na nota média no atributo aparência, como pode ser observado entre as amostras A e B, e entre as amostras C e D, Tabela 4. O mesmo comportamento pode ser observado para o aumento de U, em que ocorreu queda nas notas médias entre as amostras A e C, e entre as amostras B e D. Tanska et al. (2017) também observaram queda na nota do atributo aparência em snacks com o incremento de S. platensis. A amostra A, que apresentou a maior nota média para aparência foi a que obteve um dos maiores valores de IE (211\%) (Tabela 2).

Estes resultados estão de acordo com o estudo conduzido por Liu, Hsieh, Heymann \& Huff (2000), no qual os autores correlacionam maiores notas ao atributo cor em snacks com parâmetros instrumentais de cor, a partir de valores mais elevados de $L^{*}$. Os mesmos autores ainda comentam que valores elevados de densidade aparente estão acompanhados de atributos sensoriais negativos. No desenvolvimento de snacks a base de milho enriquecidos com Spirulina sp. realizado por Tanska et al., (2017), os pesquisadores observaram decréscimo das notas com o aumento de Spirulina sp., assim como neste trabalho.

As maiores notas ao atributo odor foram observadas nas formulações A, B e E. A concentração de S. platensis, não influenciou as notas do atributo odor, uma vez que as formulações com notas mais elevadas continham concentrações distintas, como pode ser observado nas Tabela 1 e 4. A incorporação de S. platensis em sonhos e bebida láctea não interferiu na avaliação sensorial quanto ao atributo odor (Lemes, Takeuchi et al., 2016; Guido et al., 2016). No entanto, em snacks de milho foi observado decréscimo das notas atribuídas ao aroma com o aumento deste componente (Tanska et al., 2017).

$\mathrm{O}$ atributo textura está relacionado às propriedades mecânicas crocância e dureza dos produtos extrusados, que são percepções humanas associadas à expansão e a estrutura do produto. No atributo textura, o consumidor avalia crocância e dureza dos snacks (Ding et al., 2005). Assim como em aparência e cor, a textura também pode ser influenciada pelo IE e DA dos snacks. O aumento da porosidade em decorrência da formação de bolhas de ar na camada mais interna e o colapso das bolhas na camada mais externa gera maior rigidez. A camada externa do snack é importante para o controle de umidade a manutenção da textura crocante desejável (Brennan et al., 2013).

Os maiores valores de crocância (Tabela 3) foram observados nas amostras A (28) e B (25), as quais também apresentaram baixa DA, 329 e 323 g. L L (Tabela 3), respectivamente, que podem ter contribuído com maior porosidade e crocância, e consequentemente refletiu em maiores notas para o atributo sensorial textura. No entanto, a umidade de alimentação mais elevada nas formulações C e D pode ter contribuído aos menores valores observados no atributo textura (Tabela 4).

O incremento de $S$. platensis e de subprodutos agroindustriais pode apresentar resposta diversa em relação ao atributo sabor dos alimentos. Nesse trabalho observou-se que as notas para este parâmetro não diferiram entre si ( $p>0,05$ ), as quais foram próximas a 6,0 que correspondem a resposta 'gostei ligeiramente' na escala hedônica utilizada nesse estudo.

A maior nota média concedida ao atributo impressão global foi dada à formulação A (6,2 - gostei ligeiramente), Tabela 4, 
com a menor concentração de SP e U (2,5 e $18 \mathrm{~g} .100 \mathrm{~g}^{-1}$, respectivamente) e se diferiu apenas da D (5,2 - indiferente), Tabela 4, com a maior concentração de SP e U (7,5 e 26 g. $100 \mathrm{~g}^{-1}$, respectivamente). Assim como neste trabalho, Tanska et al. (2017) observaram queda das notas de impressão global com o aumento de Spirulina sp.

Figura 9. Efeito do conteúdo de S. platensis (SP) e umidade de alimentação (U) sobre os atributos sensoriais dos snacks. A) Aparência; B) cor; C) odor; D) textura; E) impressão global.

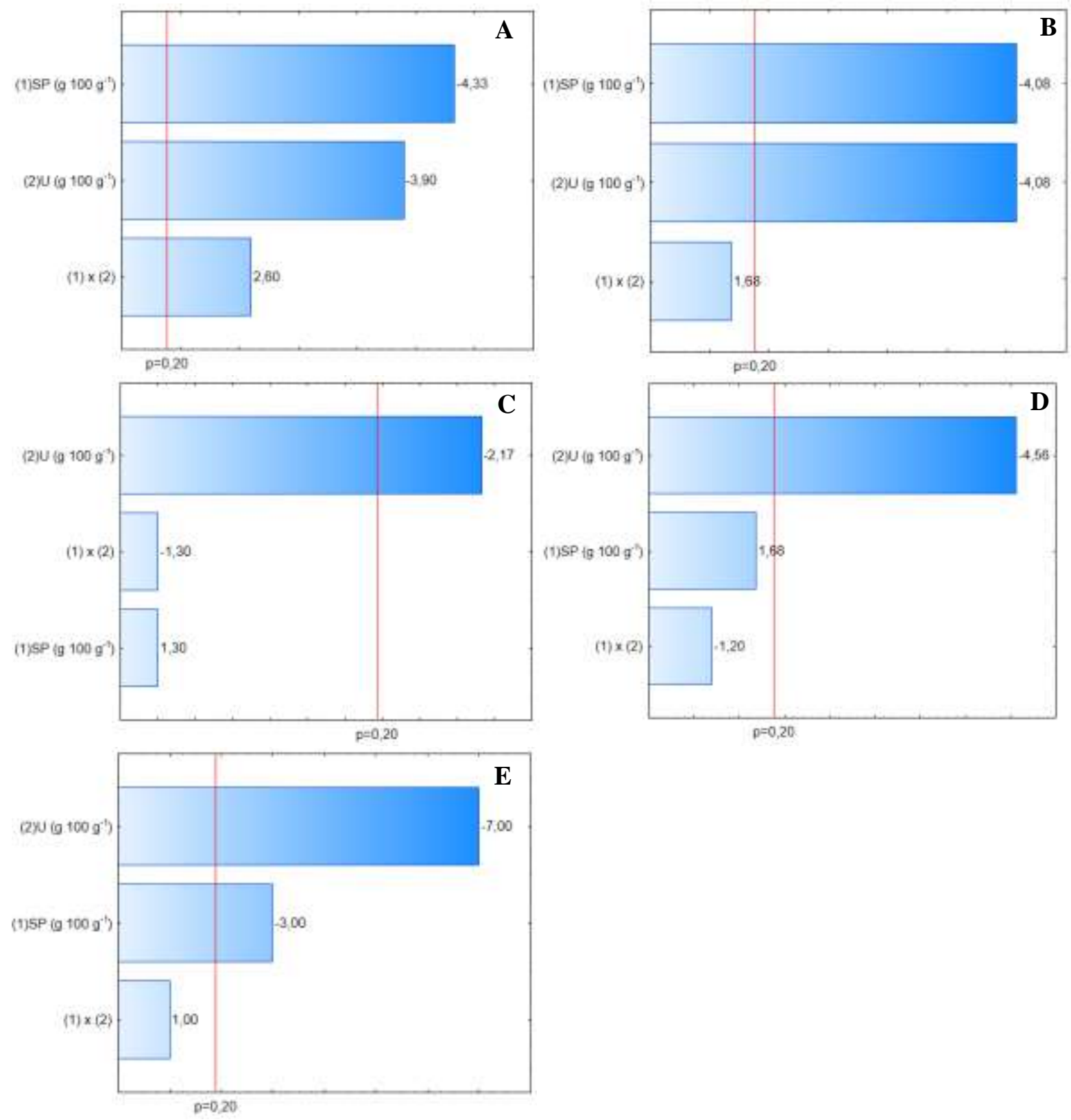

Fonte: Autores.

O índice de aceitabilidade (IA) dos snacks variaram de 58 a $73 \%$. Estes valores foram obtidos a partir dos dados de impressão global. Estes resultados mostram que a incorporação de S. platensis em snacks em níveis mais elevados, de 5 a 7,5 \%, como nas formulações E e B, respectivamente, apresentam grande potencial de aplicação, uma vez que um produto com boa aceitação deve apresentar IA superior a 70\% (Damasceno et al., 2016).

Neste trabalho, as formulações de snacks receberam o mesmo conteúdo de farinha de subprodutos de laranja e de palmito pupunha, no entanto, após o processo de extrusão os valores de fibras alimentares totais variaram entre as amostras, ao passo que 
as amostras com maiores IA (>70\%) foram as B e E, as quais apresentaram menores valores de fibras alimentares totais, 8,57 e

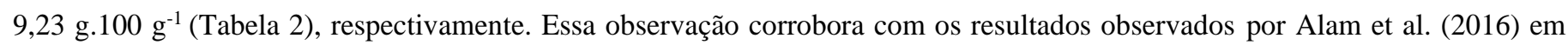
snacks que incluíram subprodutos do processamento de cenoura e couve-flor, onde, as melhores aceitações ocorreram em condições de menores incorporações dos subprodutos, menor conteúdo de fibras alimentares.

Tabela 4. Notas médias da análise sensorial a partir da escala hedônica dos snacks formulados

\begin{tabular}{|c|c|c|c|c|c|c|c|c|c|}
\hline Amostras & $\begin{array}{c}\mathrm{X}_{1} \\
(\mathrm{SP})\end{array}$ & $\begin{array}{c}\mathrm{X}_{2} \\
(\mathrm{U})\end{array}$ & Aparência & Cor & Odor & Textura & Sabor & $\begin{array}{c}\text { Impressão } \\
\text { Global }\end{array}$ & $\begin{array}{c}\text { Índice de } \\
\text { Aceitabilidade } \\
(\%)\end{array}$ \\
\hline $\mathrm{A}$ & $-1(2,5)$ & $-1(18)$ & $5,6 \pm 2,0^{\mathrm{a}}$ & $5,7 \pm 1,8^{\mathrm{a}}$ & $5,7 \pm 1,2^{\mathrm{ab}}$ & $6,0 \pm 1,9^{\mathrm{ab}}$ & $6,1 \pm 1,8^{\mathrm{a}}$ & $6,2 \pm 1,6^{\mathrm{a}}$ & 69 \\
\hline B & $+1(7,5)$ & $-1(18)$ & $4,0 \pm 2,1^{b}$ & $4,5 \pm 1,8^{b}$ & $6,3 \pm 1,3^{\mathrm{a}}$ & $6,6 \pm 1,5^{\mathrm{a}}$ & $6,3 \pm 1,8^{\mathrm{a}}$ & $5,8 \pm 1,3^{\mathrm{ab}}$ & 72 \\
\hline $\mathrm{C}$ & $-1(2,5)$ & $+1(26)$ & $4,1 \pm 2,1^{\mathrm{b}}$ & $4,5 \pm 1,9^{\mathrm{b}}$ & $5,5 \pm 1,3^{\mathrm{b}}$ & $5,3 \pm 2,0^{b}$ & $6,0 \pm 1,7^{\mathrm{a}}$ & $5,4 \pm 1,7^{\mathrm{ab}}$ & 60 \\
\hline $\mathrm{D}$ & $+1(7,5)$ & $+1(26)$ & $3,7 \pm 2,1^{\mathrm{b}}$ & $4,0 \pm 1,9^{\mathrm{b}}$ & $5,5 \pm 1,4^{b}$ & $5,4 \pm 1,8^{b}$ & $5,5 \pm 2,2^{\mathrm{a}}$ & $5,2 \pm 1,7^{\mathrm{b}}$ & 58 \\
\hline $\mathrm{E}$ & $0(5,0)$ & $0(22)$ & $4,7 \pm 1,9^{\mathrm{ab}}$ & $4,8 \pm 1,8^{\mathrm{ab}}$ & $5,7 \pm 1,4^{\mathrm{ab}}$ & $6,0 \pm 1,6^{\mathrm{ab}}$ & $6,0 \pm 1,9^{a}$ & $5,8 \pm 1,4^{\mathrm{ab}}$ & 73 \\
\hline $\mathrm{F}$ & $0(5,0)$ & $0(22)$ & $4,3 \pm 2,0^{b}$ & $4,4 \pm 1,9^{b}$ & $5,3 \pm 1,4^{\mathrm{b}}$ & $5,6 \pm 1,7^{b}$ & $6,2 \pm 1,7^{\mathrm{a}}$ & $5,7 \pm 1,7^{\mathrm{ab}}$ & 63 \\
\hline $\mathrm{G}$ & $0(5,0)$ & $0(22)$ & $4,7 \pm 2,0^{\mathrm{ab}}$ & $4,7 \pm 1,9^{\mathrm{ab}}$ & $5,3 \pm 1,3^{\mathrm{b}}$ & $5,9 \pm 1,9^{b}$ & $6,1 \pm 1,7^{\mathrm{a}}$ & $5,9 \pm 1,7^{\mathrm{ab}}$ & 66 \\
\hline \multirow{2}{*}{\multicolumn{3}{|c|}{$\begin{array}{l}\text { p-valor (normalidade) } \\
\text { p-valor (Kruskal-Wallis) }\end{array}$}} & $<0,01$ & $<0,01$ & $<0,01$ & $<0,01$ & $<0,01$ & $<0,01$ & NA \\
\hline & & & $<0,001$ & $<0,001$ & $<0,001$ & $<0,001$ & 0,376 & 0,005 & NA \\
\hline
\end{tabular}

NOTA: Variáveis independentes codificadas $\left(\mathrm{X}_{1}\right.$ e $\left.\mathrm{X}_{2}\right)$, e entre parênteses, variáveis independentes reais, onde SP corresponde à S. Platensis e $\mathrm{U}$ à umidade em $\mathrm{g} 100 \mathrm{~g}^{-1}$; Valores representam média \pm desvio padrão $(\mathrm{n}=75)$.

Letras diferentes na mesma coluna indicam diferença significativa entre as médias ( $p \leq 0,05)$. NA= não aplicável

Fonte: Autores.

A adição de $S$. platensis em níveis elevados contribuiu com o índice de aceitabilidade dos snacks e não afetou o atributo sabor, porém influenciaram negativamente na avaliação sensorial dos atributos aparência, cor e impressão global dos snacks. Analisando o incremento nutricional dos snacks desenvolvidos, o produto pode estimular o consumo por um público alternativo interessado em hábitos de alimentação saudável e que provoque menos impactos negativos ao meio ambiente. Quando se considera esse grupo de consumidores, a aceitação sensorial pode ser maior para os produtos desenvolvidos, uma vez que diversos fatores podem influenciar na aceitação de produtos, entre eles o conhecimento dos benefícios que estes produtos podem proporcionar à saúde. Desta forma, evidencia-se como viável a oportunidade de incrementar o valor nutricional de snacks extrusados com $S$. platensis e subprodutos agroindustriais, de laranja e palmito pupunha, com aceitação sensorial satisfatória.

\section{Conclusão}

Os snacks de arroz e $S$. platensis com subprodutos de laranja e de palmito pupunha podem ser uma opção mais nutritiva que produtos similares comerciais. A S. platensis contribuiu no aumento do conteúdo de proteínas dos snacks. Quando comparados a snack comercial similar, este aumento foi de 15 a $48 \%$. As fibras contidas nas farinhas de laranja e de palmito pupunha, contribuíram para um produto com 320 a $380 \%$ mais fibra alimentar total que um snack extrusado comercial. O valor energético variou de 87 a $89 \mathrm{kcal}$ por porção de $25 \mathrm{~g}$. A atividade antioxidante foi afetada positivamente pela interação de $S$. platensis e umidade. O aumento da capacidade redutora Folin-Ciocalteu se correlacionou com o aumento de SP, enquanto os compostos fenólicos totais não foram influenciados pelas condições testadas. A substituição de farinha de arroz por farinha de palmito pupunha, farinha de laranja e SP nas formulações dos snacks promoveu aumento da atividade antioxidante em mais de $1000 \%$, esta substituição das farinhas de subprodutos também contribuiu para o aumento do conteúdo de fibras alimentares.

Os valores de SP e umidade de alimentação estudados não apresentaram efeito sobre índices de expansão, de solubilidade em água, de absorção de água e de absorção de óleo. A densidade aparente dos snacks foi influenciada positivamente pela umidade de alimentação, e as formulações com maiores proporções de SP apresentaram menores valores de atividade de água.

As proporções de U e SP promoveram efeitos negativos sobre as propriedades mecânicas, crocância e dureza, ao passo 
que a interação das variáveis independentes promoveu efeitos positivos. Nos parâmetros colorimétricos, menores valores de SP e U nas formulações geraram snacks mais claros, o maior valor de $L^{*}$ foi atribuído à amostra com menores valores de SP e U. Os maiores valores de aceitabilidade dos snacks, amostras B e E, com IA de 72 e $73 \%$, respectivamente, ocorreram com níveis de intermediário a elevado (5 e 7,5 g.100"-1, respectivamente) de $S$. platensis.

Portanto, este estudo contribui na elucidação aplicação de subprodutos de laranja e de palmito pupunha no enriquecimento nutricional de snacks extrusados como alternativas sustentáveis e de baixo custo na produção de alimentos, sobretudo a incorporação de S. platensis contribuiu no aumento de proteína e atividade antioxidante, sendo assim os snacks desenvolvidos apresentaram adequadas características tecnológicas e sensoriais, tornando sua aplicação viável.

\section{Agradecimentos}

Os autores agradecem à técnica de laboratório Denise Mendes. Agradecem também às Companhias Prozyn, Marbbel pela doação das enzimas e dos subprodutos de palmito pupunha respectivamente. O presente trabalho foi realizado com apoio da Coordenação de Aperfeiçoamento de Pessoal de Nível Superior - Brasil (CAPES) - Código de Financiamento 001.

\section{Referências}

Alam, M. S., Pathania, S. \& Sharma, A. (2016). Optimization of the extrusion process for development of high fibre soybean-rice ready-to-eat snacks using carrot pomace and cauliflower trimmings. LWT - Food Science and Technology, 74, 135-144. 10.1016/j.1wt.2016.07.031

Anderson, R. A., Conway, H. F. Y. \& Peplinski, A. J. (1970). Gelatinization of corn grits by roll cooking, extrusion cooking and steaming. Starch Stärke. 22(4), 130-135. 10.1002/star.19700220408

AOAC. Official Methods of Analysis of the Association of Analytical Chemists (1995). (16a ed)

Ascheri, D. P. R., Ascheri, J. L. R. \& Carvalho, C. W. P. V. (2006). Caracterização da farinha de bagaço de jabuticaba e propriedades funcionais dos extrusados. Ciência e Tecnologia de Alimentos, 26(4), 897-905. 10.1590/S0101-20612006000400029

Belive (2021). Snack de arroz sabor cebola e salsa belive. https://belivebefree.com.br/produto/snack-de-arroz-sabor-cebola-e-salsa-belive/

Bender, A. B. B., Luvielmo, M. M., Loureiro, B. B., Speroni, C. S., Boligon, A. A., Silva, L. P. \& Penna, N. G. (2016). Obtenção e caracterização de farinha de casca de uva e sua utilização em snack extrusado. Brazilian Journal of Food Technology, 19, e2016010. 10.1590/1981-6723.1016

Bezerra, M. A., Santelli, R. E., Oliveira, E. P.; Villar, L. S. \& Escaleira, L. A. (2008). Response surface methodology (RSM) as a tool for optimization in analytical chemistry. Talanta, 76(5), 965-977. 10.1016/j.talanta.2008.05.019

Bolanho, B. C., Danesi, E. D. G. \& Beléia, A. D. P. (2014). Characterization of flours made from peach palm (Bactris gasipaes Kunth) by-products as a new food ingredient. Journal of Food and Nutrition Research, 53(1), 51-59. https://www.vup.sk/index.php?

Bolanho, B. C., Egea, M. B., Jácome, A. L. M., Campos, I., Carvalho, J. C. M. \& Danesi, E. D. G. (2014). Antioxidant and nutritional potential of cookies enriched with Spirulina platensis and sources of fibre. Journal of Food and Nutrition Research, 53(2), 171-179. https://www.vup.sk/index.php?mainID=2\&navID=36\&version=2\&volume=53\&issue=2

Bolanho, B. C., Danesi, E. D. G. \& Beléia, A. D. P. (2015). Carbohydrate composition of peach palm (Bactris gasipaes Kunth) by-products flours. Carbohydrate Polymers, 124, 196-200. 10.1016/j.carbpol.2015.02.021

Brand-Williams, W., Cuvelier, M. \& Berset, C. L. W. T. (1995). Use of a free radical method to evaluate antioxidant activity. LWT - Food Science and Technology, 28(1), 25-30. 10.1016/S0023-6438(95)80008-5

Brasil (2001). Ministério da Saúde. Agência Nacional de Vigilância Sanitária - ANVISA. Resolução RDC n ${ }^{\circ} 12$ de 2 de janeiro de 2001 . Estabelece os padrões microbiológicos para alimentos. http://portal.anvisa.gov.br/

Brasil. (2003). Ministério da Saúde. Agência Nacional de Vigilância Sanitária - ANVISA. Resolução RDC nº 359 de 23 de dezembro de 2003 que dispõe sobre o Regulamento técnico de porções de alimentos embalados para fins de rotulagem nutricional. http://portal.anvisa.gov.br/

Brasil. (2005). Ministério da Saúde. Agência Nacional de Vigilâcia sanitaria - ANVISA. Resolução RDC nº 269 , de 22 de setembro de 2005. Dispõe sobre o regulamento técnico sobre a ingestão diária recomendada (IDR) de proteína, vitaminas e minerais. http://portal.anvisa.gov.br/

Brennan, M. A., Monro, J. A. \& Brennan, C. S. (2008). Effect of inclusion of soluble and insoluble fibres into extruded breakfast cereal products made with reverse screw configuration. International Journal of Food Science \& Technology, 43(12), 2278-2288. 10.1111/j.1365-2621.2008.01867.x

Brennan, M. A., Desbyshire, E., Tiwari, B. K. \& Brennan, C. S. (2013). Ready-to-eat snack products: the role of extrusion technology in developing consumer acceptable and nutritious snacks. International Journal of Food Science \& Technology, 48(5), 893-902. 10.1111/ijfs.12055 
Brito, V. H. D. S., \& Cereda, M. P. (2015). Método para determinação de volume específico como padrão de qualidade do polvilho azedo e sucedâneos. Brazilian journal of food technology, 18(1), 14-22. 10.1590/1981-6723.0214

Damasceno, K. A., Gonçalves, C. A. A., Pereira, G. S., Costa, L. L., Campagnol, P. C. B., Almeida, P. L. \& Arantes-Pereira, L. (2016). Development of Cereal Bars Containing Pineapple Peel Flour (Ananas comosus L. Merril). Journal of Food Quality, 39(5), 417-424. 10.1111/jfq.12222

Danesi, E. D. G., Granato, D., Iwassa, I. J., Pinzon, C. \& Bolanho, B. C. (2018). Effects of industrial by-products from orange, peach palm and soybean on the quality traits and antioxidant activity of flours: a response surface approach. International Food Research Journal, 25(3), 1219-1227. http://web.b.ebscohost.com/ehost/pdfviewer/pdfviewer?vid=1\&sid=ac6631e8-ae0c-49ef-a761-1f1fbf80b43a\%40sessionmgr101

Deshpande, H. W. \& Poshadri, A. (2011). Physical and sensory characteristics of extruded snacks prepared from Foxtail millet based composite flours. International Food Research Journal, 18, 2, 751-756. http://web.a.ebscohost.com/ehost/pdfviewer/pdfviewer?v id=1\&sid=6681834a-a8c5-459f-bdf3427e1c0af3cc\%40sessionmgr4008

Ding, Q., Ainsworth, P., Tucker, G. \& Marson, H. (2005). The effect of extrusion conditions on the physicochemical properties and sensory characteristics of ricebased expanded snacks. Journal of Food Engineering, 66(3), 283-289. 10.1016/j.jfoodeng.2004.03.019

Ejike, C. E. C. C., Collins, S. A., Balasuriya, N., Swanson, A. K., Mason, B. \& Udenigwe, C. C. (2017). Prospects of microalgae proteins in producing peptidebased functional foods for promoting cardiovascular health. Trends in Food Science \& Technology, 59, 30-36. 10.1016/j.tifs.2016.10.026

Fiorda, F. A., Soares, M. S. Jr, Silva, F. A. da, Moura, C. M. A. de, \& Grossmann, M. V. E. (2015). Physical quality of snacks and technological properties of pregelatinized flours formulated with cassava starch and dehydrated cassava bagasse as a function of extrusion variables. LWT-Food science and technology, 62(2), 1112-1119. 10.1016/j.lwt.2015.02.030

Fradique, M., Batista, A. P., Nunes, M. C., Gouveia, L., Bandarra, N. M. \& Raymundo, A. (2010). Incorporation of Chlorella vulgaris and Spirulina maxima biomass in pasta products. Part 1: Preparation and evaluation. Journal of the Science of Food and Agriculture, 90(10), 1656-1664. 10.1002/jsfa.3999

Goes, E. S. D. R., Souza, M. L. R. D., Campelo, D. A. V., Yoshida, G. M., Xavier, T. O., Moura, L. B. D. \& Monteiro, A. R. G. (2015). Extruded snacks with the addition of different fish meals. Food Science and Technology, 35(4), 683-689. 10.1590/1678-457X.6818

Granato, D., Calado, V. M. A. \& Jarvis, B. (2014). Observations on the use of statistical methods in food science and technology. Food Research International, 55, 137-149. 10.1016/j.foodres.2013.10.024

Granato, D., Karnopp, A. R. \& Ruth, S. M. Van (2015). Characterization and comparison of phenolic composition, antioxidant capacity and instrumental taste profile of juices from different botanical origins. Journal of the Science of Food and Agriculture, 95(10), 1997-2006. 10.1002/jsfa.6910

Grasso, S. (2020). Extruded snacks from industrial by-products: A review. Trends in Food Science \& Technology, 99, 284-294. 10.1016/j.tifs.2020.03.012

Guido, E. S., Corrêa, C. P. \& Danesi, E. D. G. (2016). Bebida láctea potencialmente probiótica adicionada de biomassa de Spirulina platensis e fibras de mandioca. In: Danesi, E. D. G. et al., Spirulina platensis: Potencial para Desenvolvimento de Alimentos. Saarbrucken: Novas Edições Acadêmicas.

Harper, J. M. \& Clark, J. P. (1979) Food extrusion. CRC Critical Reviews in Food Science and Nutrition, 11(2), 155-215. 10.1080/10408397909527262

ISO (2014). Sensory analysis - Methodology: General guidance for conducting hedonic tests with consumers in a controlled area. ISO 11136.

Joshi, S. M. R., Bera, M. B. \& Panesar, P. S. (2014). Extrusion cooking of Maize/Spirulina mixture: Factors affecting expanded product characteristics and sensory quality. Journal of Food Processing and Preservation, 38, 655-664. 10.1111/jfpp.12015

Kadan, R. S., Robinson, M. G., Thibodeaux, D. P. \& Peppermen, A. B. Jr. (2001). Texture and other properties of whole rice bread. Journal of Food Science, 66(7), 940-944. 10.1111/j.1365-2621.2001.tb08216.x

Larrea, M. A., Chang, Y. K. \& Martinez-Bustos, F. (2005). Some functional properties of extruded orange pulp and its effect on the quality of cookies. LWT - Food Science and Technology, 38, 213-220. 10.1016/j.1wt.2004.05.014

Lemes, A. C., Takeuchi, K. P., Carvalho, J. C. M. \& Danesi, E. D. G. (2012). Fresh pasta production enriched with Spirulina platensis biomass. Brazilian Arquives of Biology and Technology, 55(5), 741-750. 10.1590/S1516-89132012000500014

Lemes, A. C.; Takeuchi, K. P., Frata, M. T. \& Danesi, E. D. G. (2016) Sonho de mandioca enriquecido com biomassa de Spirulina platensis. In: Danesi, E. D. G. et al., Spirulina platensis: Potencial para Desenvolvimento de Alimentos. Saarbrucken: Novas Edições Acadêmicas.

Lemes, A. C., Bolanho, B. C., Marques, C., Simões, D. R. S., Fabro, L. F., Egea, M. B.; Leone, R. S. \& Danesi, E. D. G. (2016). Sopas com Spirulina platensis e subproduto de palmito pupunha In: Danesi, E. D. G. et al., Spirulina platensis: Potencial para Desenvolvimento de Alimentos. Saarbrucken: Novas Edições Acadêmicas.

Liu, Y., Hsieh, F., Heymann, H., \& Huff, H. E. (2000). Effect of process conditions on the physical and sensory properties of extruded oat-corn puff. Journal of food science, 65(7), 1253-1259. 10.1111/j.1365-2621.2000.tb10274.X

Lupatini, A. L., Bispo, L. O., Colla, L. M., Costa, J. A. V., Canan, C. \& Colla, E. (2017). Protein and carbohydrate extraction from S. platensis biomass by ultrasound and mechanical agitation. Food Research International, 99, 1028-1035. 10.1016/j.foodres.2016.11.036

Lucas, B. F., Morais, M. G. D., Santos, T. D. \& Costa, J. A. V. (2017). Effect of Spirulina addition on the physicochemical and structural properties of extruded snacks. Food Science and Technology, 37, SPE, 16-23. 10.1590/1678-457x.06217

Lucas, B. F., Morais, M. G. D., Santos, T. D. \& Costa, J. A. V. (2018). Spirulina for snack enrichment: Nutritional, physical and sensory evaluations. LWT - Food 
Science and Technology, 90, 270-276. 10.1016/j.1wt.2017.12.032

Marco, E. R., Steffolani, M. E., Martínez, C. S. \& León, A. E. (2014). Effects of Spirulina biomass on the technological and nutritional quality of bread wheat pasta. LWT - Food Science and Technology, 58, 102-108. 10.1016/j.lwt.2014.02.054

Margraf, T., Karnopp, A. R., Rosso, N. D. \& Granato, D. (2015). Comparison between Folin-Ciocalteu and Prussian Blue assays to estimate the total phenolic content of juices and teas using 96-well microplates. Journal of Food Science, 80(11), 2394-2403. 10.1111/1750-3841.13077

Morsy, O. M., Sharoba, A. M., El-Desouky, A. I., Bahlol, H. E. M. \& El-Mawla, E. M. (2014). Production and evaluation of some extruded food products using Spirulina algae. Annals of Agricultural Science, 52(4), 329-342. 10.21608/ASSJM.2014.111899

Myers, R. H., Montgomery, D. C. \& Anderson-Cook, C. M. (2016). Response surface methodology: process and product optimization using designed experiments. Hobohen, New Jersey: John Wiley \& Sons.

Navacchi, M. F. P., Takeuchi, K. P. \& Danesi, E. D. G. (2016). Bolo de mandioca enriquecido com biomassa de Spirulina platensis e farelo de fecularias. In: Danesi, E. D. G. et al., Spirulina platensis: Potencial para Desenvolvimento de Alimentos. Saarbrucken: Novas Edições Acadêmicas.

Navarro Cortez, R. O., Gómez-Aldapa, C. A., Aguilar-Palazuelos, E., Delgado-Licon, E., Castro Rosas, J., Hernández-Ávila, J., Solís-Soto, A., Ochoa-Martínez \& Medrano-Roldán, H. (2016). Blue corn (Zea mays L.) with added orange (Citrus sinensis) fruit bagasse: novel ingredients for extruded snacks. CyTA-Journal of Food, 14(2), 349-358. 10.1080/19476337.2015.1114026

Oliveira, L. C., Rosell; C. M. \& Steel, C. J. (2015). Effect of the addition of whole-grain wheat flour and of extrusion process parameters on dietary fibre content, starch transformation and mechanical properties of a ready-to-eat breakfast cereal. International Journal of Food Science \& Technology, 50(6), 1504-1514. $10.1111 /$ ijfs. 12778

Oliveira, L. C., Schmiele, M. \& Steel, C. J. (2017). Development of whole grain wheat flour extruded cereal and process impacts on color, expansion, and dry and bowl-life texture. LWT - Food Science and Technology, 75, 261-270. 10.1016/j.1wt.2016.08.064

Romero-Lopez, M. R., Osorio-Diaz, P.; Bello-Perez, L. A., Tovar, J. \& Bernardino-Nicanor, A. (2011). Fiber concentrate from orange (Citrus sinensis L.) bagase: Characterization and application as bakery product ingredient. International Journal of Molecular Sciences, 12(4), 2174-2186. 10.3390/ijms12042174

Santos, J. S., Deolindo, C. T. P., Esmerino, L. A., Genovese, M. I., Fujita, A., Marques, M. B., Rosso, N. D., Daguer, H., Valese, A. C. \& Granato, D. (2016). Effects of time and extraction temperature on phenolic composition and functional properties of red rooibos (Aspalathus linearis). Food Research International, 89, 476-487. 10.1016/j.foodres.2016.08.041

Santos, I. L., Schmiele, M., Aguiar, J. P. L., Steel, C. J., Silva, E. P., \& Souza, F. D. C. D. A. (2020). Evaluation of extruded corn breakfast cereal enriched with whole peach palm (Bactris gasipaes, Kunth) Flour. Food Science and Technology, 40(2), 458-464. 10.1590/fst.04019

Selani, M. M., Brazaca, S. G. C., Dias, C. T. S., Ratnayake, W. S., Flores, R. A. \& Bianchini, A. (2014). Characterization and potential application of pineapple pomace in an extruded product for fibre enhancement. Food Chemistry, 163, 23-30. 10.1016/j.foodchem.2014.04.076

Singleton, V. L., Orthofer, R. \& Lamuela-Raventós, R. M. (1999). Analysis of total phenols and other oxidation substrates and antioxidants by means of folinciocalteu reagent. In: Methods in Enzymology. Academic press. 10.1016/S0076-6879(99)99017-1

Souza, L. B., Leonel, M. \& Mischan, M. M. (2007). Effect of extrusion conditions on the physical properties of snacks of cassava starch and orange pulp. Alimentos e Nutrição, 18(1), 83-9.

Steel, C. J., Leoro, M. G. V., Schmiele, M., Ferreira, R. E. \& Chang, Y. K. (2012). Thermoplastic extrusion in food processing. In: Thermoplastic elastomers, 265.

Tanska, M., Konopka, I. \& Ruszkowska, M. (2017). Sensory, physico-chemical and water sorption properties of corn extrudates enriched with Spirulina. Plant Foods for Human Nutrition, 72(3), 250-257. 10.1007/s11130-017-0628-z

Walter, M., Marchezan, E. \& Avila, L. A. (2008). Arroz: composição e características nutricionais. Ciência Rural, 38(4), 1184-1192. 10.1590/S010384782008000400049

Zortéa-Guidolin, M. E. B., Carvalho, C. W. P., Godoy, R. C. B., Demiate, I. M. \& Scheer, A. P. (2017). Influence of extrusion cooking on in vitro digestibility, physical and sensory properties of Brazilian pine seeds flour (Araucaria Angustifolia). Journal of Food Science, 82(4), 977-984. 10.1111/1750-3841.13686 